ПО МАТЕРИАЛАМ КЛИНИЧЕСКИХ РЕКОМЕНДАЦИЙ ЕВРОПЕЙСКОЙ ТИРЕОИДНОЙ АССОЦИАЦИИ ПО ДИАГНОСТИКЕ И ЛЕЧЕНИЮ ТИРЕОТОКСИКОЗА ПРИ БОЛЕЗНИ ГРЕЙВСА 2018 ГОДА

\title{
() В.В. Фадеев
}

Первый Московский государственный медицинский университет им. И.М. Сеченова (Сеченовский Университет), Москва, Россия

Болезнь Грейвса (БГ) - системное аутоиммунное заболевание, характеризующееся инфильтрацией тканей, экспрессирующих рецептор тиреотропного гормона (ТТГ), а также Т-лимфоцитами, специфичными к антигенам щитовидной железы (ЩЖ). При БГ стимулирующие антитела (АТ) активируют рецептор к ТТГ (рТТГ), что приводит к гиперплазии ЩЖ и нерегулируемой гиперпродукции и гиперсекреции тиреоидных гормонов. Диагностика БГ базируется на лабораторном подтверждении тиреотоксикоза, повышении уровня АТ-рТТГ, обнаружении гиперваскуляризации и гипоэхогенности ЩЖ при УЗИ в сочетании с эндокринной орбитопатией (ЭОП). Определение уровня АТ-рТТГ необходимо для дифференциальной диагностики, прогнозирования риска рецидива тиреотоксикоза и при беременности. Тиреотоксикоз при БГ купируется назначением тиреостатиков, которые подавляют синтез тиреоидных гормонов; радикальное лечение подразумевает разрушение ткани ЩЖ при помощи радиоактивного йода (131) или ее хирургическое удаление (тиреоидэктомию). Пациентам с впервые выявленной БГ в большинстве случаев назначается терапия тиамазолом (ТМ3), который рассматривается как препарат первого выбора, сроком 12-18 месяцев. Детям с БГ традиционно рекомендуется более длительный курс терапии ТМ3 - обычно на 24-36 месяцев. Если у пациента сохраняется повышение уровня АТ-рТТГ спустя 12-18 месяцев тиреостатической терапии, она, в части случаев, может быть продолжена с повторным определением АТ-рТТГ еще через 12 месяцев; альтернативой является ${ }^{131}$ или тиреоидэктомия. Женщин, получающих терапию ТМЗ, при планировании беременности или в ее І триместре, рекомендуется перевести на пропилтиоурацил (ПТУ). В случае развития рецидива или сохранения тиреотоксикоза после окончания курса тиреостатической терапии пациенту показано радикальное лечение. Тем не менее в отдельных случаях тиреостатическая терапия может проводиться длительно. Тиреоидэктомию следует доверять специализированным эндокринным хирургам, имеющим достаточный опыт проведения этой операции. Терапия ${ }^{131}$ противопоказана пациентам с тяжелой активной орбитопатией (ЭОП) и должна проводиться на фоне профилактического назначения глюкокортикоидов (ГК) при умеренно активной ЭОП.

КЛЮЧЕВЫЕ СЛОВА: Тиреотоксикоз; болезнь Грейвса; болезнь Базедова; тиреостатические препараты; терапия радиоактивным йодом; тиреоидэктомия; эндокринная орбитопатия

\section{REVIEW OF EUROPEAN THYROID ASSOCIATION GUIDELINE (2018) FOR THE MANAGEMENT OF GRAVES' HYPERTHYROIDISM}

\author{
(c) Valentin V. Fadeyev
}

\section{I.M. Sechenov First Moscow State Medical University (Sechenov University), Moscow, Russia}

Graves' disease (GD) is a systemic autoimmune disorder characterized by the infiltration of thyroid antigen-specific T-cells into thyroid-stimulating hormone receptor (TSH-R)-expressing tissues. Stimulatory autoantibodies (Ab) in GD activate the TSH-R leading to thyroid hyperplasia and unregulated thyroid hormone production and secretion. Diagnosis of GD is straightforward in a patient with biochemically confirmed thyrotoxicosis, positive TSH-R-Ab, a hypervascular and hypoechoic thyroid gland (ultrasound), and associated orbitopathy. In GD, measurement of TSH-R-Ab is recommended for an accurate diagnosis/differential diagnosis, prior to stopping antithyroid drug (ATD) treatment and during pregnancy. Graves' hyperthyroidism is treated by decreasing thyroid hormone synthesis with the use of ATD, or by reducing the amount of thyroid tissue with radioactive iodine (RAI) treatment or total thyroidectomy. Patients with newly diagnosed Graves' hyperthyroidism are usually medically treated for 12-18 months with methimazole (MMI) as the preferred drug. In children with GD, a 24- to 36-month course of MMI is recommended. Patients with persistently high TSH-R-Ab at 12-18 months can continue MMI treatment, repeating the TSH-R-Ab measurement after an additional 12 months, or opt for therapy with RAl or thyroidectomy. Women treated with MMI should be switched to propylthiouracil when planning pregnancy and during the first trimester of pregnancy. If a patient relapses after completing a course of ATD, definitive treatment is recommended; however, continued long-term low-dose MMI can be considered. Thyroidectomy should be performed by an experienced high-volume thyroid surgeon. RAI is contraindicated in Graves' patients with active/severe orbitopathy, and steroid prophylaxis is warranted in Graves' patients with mild/active orbitopathy receiving RAI. 
The literature review presented in this article does not claim to be a full-fledged systematic review, not only for the reason that to date, only 51 works have been found at the time of writing in the databases for the keywords «thyroid and COVID-19» and "adrenal and COVID-19», after excluding duplicates, but also because these messages themselves contain little information and are mainly based on analogies with previously existing viral infections and their role in the development of hypothalamus-pituitary axis pathology-adrenal glands and hypothalamus-pituitary-thyroid.

KEYWORDS: Graves' hyperthyroidism management; antithyroid drugs; radioiodine therapy; thyroidectomy; Graves' orbitopathy.

\section{КОММЕНТАРИЙ ОТ АВТОРА ПЕРЕВОДА}

Рекомендации ЕTA по лечению тиреотоксикоза при болезни Грейвса были опубликованы в журнале European Thyroid Journal в конце 2018 г. Здесь мы приводим незначительно сокращенный и адаптированный перевод текста рекомендаций, сделанный автором этой статьи. Учитывая важность этих рекомендаций для клинической работы, я решил перевести их полностью, то есть не только сами рекомендации, которых 50, но и комментарии к ним с соответствующими литературными ссылками, что имеет большое научное значение. Структура рекомендаций и весь графический материал полностью сохранены и представлены в этой статье. Мой перевод неизбежно содержит акценты моего понимания проблемы, при этом русская интерпретация английского текста неизбежно оказывается более объемной. Интонации «может быть рекомендовано», «предлагается», «считается целесообразным», «не рекомендуется», «желательно избегать» и т.д., которые используются при переводе, могут изменить смысл написанного. Другими словами, на том русском тексте, который вы сейчас будите читать, неизбежно отразился мой творческий подход к переводу, который, на мой взгляд, должен в первую очередь служить не тексту оригинала, а русскому читателю.

\section{ЭПИДЕМИОЛОГИЯ И ПАТОГЕНЕЗ}

Гипертиреоз развивается вследствие патологического повышения синтеза и секреции тиреоидных гормонов щитовидной железой (ЩЖ) [1]. Избыток тиреоидных гормонов усиливает термогенез и основной обмен, обуславливает снижение уровня холестерина в крови и снижение системного сосудистого сопротивления. Осложнениями длительно некомпенсированного тиреотоксикоза являются похудение, остеопороз, фибрилляция предсердий, эмболические осложнения, сердечно-сосудистые заболевания [2-4]. Распространенность гипертиреоза в общей популяции составляет 1,2-1,6\% (0,5-0,6\% явный и 0,7-1,0\% субклинический) $[1,5]$. Наиболее частыми причинами стойкого длительного гипертиреоза являются болезнь Грейвса (БГ) и узловой токсический зоб. БГ - наиболее частая причина стойкого гипертиреоза в регионах с нормальным потреблением йода, с частотой новых случаев 20-30 на 100 тысяч населения в год [6]. БГ чаще развивается у женщин, среди которых ее распространенность в общей популяции достигает 1-1,5\%. Примерно у 3\% женщин и 0,5\% мужчин на протяжении их жизни развивается БГ [7]. Пик заболеваемости приходится на возраст 30-60 лет, и ее показатели выше среди афроамериканцев. Поражение ЩЖ при БГ — органоспецифическое аутоиммунное заболевание, которое обусловлено циркуляцией аутоантител (АТ), стимулирующих рецептор тиреотропного гормона (рТТГ), что приводит к развитию тиреотоксикоза и образованию зоба. АТ-рТТГ преимущественно относятся к lgG1 изотипу и транзиторно связываются с эпитопом в лейцин-богатом внеклеточном домене этого рецептора примерно в области аминокислот 20-260 [9, 10]. Рецептор ТТГ и рецептор инсулиноподобного фактора роста 1 (рИРФ-1) на поверхности тиреоцитов и орбитальных фибробластов функционально взаимодействуют, в связи с чем АТ-рТТГ могут активировать внутриклеточные каскады, идущие как от рТТГ, так и от рИРФ-1 [11]. Циркуляция стимулирующих АТ-рТТГ приводит к их связыванию с соответствующим рецептором, увеличению уровня внутриклеточного содержания цАМФ, что сопровождается стимуляцией синтеза и высвобождения тиреоидных гормонов и ростом тиреоцитов. Примерно у $30 \%$ пациентов с БГ есть родственники с этим заболеванием или с АИТ. Близнецовые исследования выявили, что вклад наследственной предрасположенности в развитие БГ составляет около 80\% [12]. Выявлена достаточно тесная ассоциация БГ с аллелями главного комплекса гистосовместимости - гаплотипами HLADR3 and HLA-DR4 [13]. Другие известные локусы, определяющие предрасположенность к БГ, кодируют антиген-4 цитотоксических Т-лимфоцитов, нерецепторной тирозин-фосфатазы-22, основной фактор-2 застежки тирозин-фосфатазы и CD-40 [14]. К предрасполагающим к развитию БГ факторам внешней среды относятся курение сигарет, высокий уровень потребления йода с пищей, стресс и беременность [15-17]. Прием оральных контрацептивов, возможно, имеет протективный эффект, как и мужской пол, что, вероятно, свидетельствует о роли половых гормонов в развитии БГ $[6,15]$.

\section{МЕТОДОЛОГИЯ РЕКОМЕНДАЦИЙ}

Сила (уровень) рекомендаций и их качество ранжированы в соответствии с системой GRADE [18]. Строгая (сильная) рекомендация обозначена как 1 (единица), слабая рекомендация - как 2 (двойка); доказательность обозначается по мере ее увеличения одним или четырьмя зачеркнутыми кружками: ООО

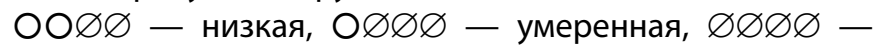
высокая.

\section{ЛАБОРАТОРНАЯ ДИАГНОСТИКА}

Уровень ТТГ в сыворотке как единственный самостоятельный тест превосходит по чувствительности и специфичности все остальные и может быть рекомендован пациентам при подозрении на тиреотоксикоз [19, 20]. Тем не менее если тиреотоксикоз клинически очевиден, диагностически более целесообразно определение ТТГ 
вместе со свободным тироксином $\left(\mathrm{T}_{4}\right)$ уже при первичном исследовании. При интактной оси гипофиз-ЩЖ соотношение уровней св. Т и ТТГ подчиняется обратному лог-линейному соотношению, то есть минимальные изменения уровня св. Т приводят к значительно большим по амплитуде изменениям уровня ТТГ. Определение уровня ТТГ существенно чувствительнее, чем прямое определение уровня тиреоидных гормонов, для выявления их избытка [21]. При явном (манифестном) тиреотоксикозе повышены уровни как св. Т , так и трийодтиронина $\left(\mathrm{T}_{3}\right)$, при подавленном уровне ТТГ; при умеренном тиреотоксикозе уровни общего и свободного $\mathrm{T}_{4}$ могут быть в референсном интервале, и только св. Т может быть повышен в сочетании с неопределяемой концентрацией ТТГ.

АТ-рТТГ являются специфическими маркерами БГ [22]. Большинство иммунометрических исследований в настоящее время используют принцип конкурентного связывания, в связи с чем определяемые антитела обозначаются как иммуноглобулины, подавляющие связывание рецептора TTГ (TBII). Такие исследования выявляют факт наличия или отсутствия АТ-рТТГ, а также их концентрацию в сыворотке, но не позволяют оценить их биологическую активность [23, 24]. Метаанализ 21 исследования показал, что диагностическая чувствительность и специфичность определения TBII методами второго и третьего поколения составили соответственно 97\% и 98\% [25]. В противоположность этому, биологические исследования, базирующиеся на клеточных технологиях [26-33], позволяют лишь отличить стимулирующие (TSAb) и блокирующие антитела к ЩЖ [34, 35]. Важно отметить, что TSAb - высокочувствительный и прогностически значимый биомаркер в том числе и экстратиреоидных проявлений БГ [36-42], а также прогностический маркер транзиторного неонатального и фетального тиреотоксикоза $[43,44]$. Внедрение в алгоритм диагностики БГ определения TSAb привело к тому, что на $46 \%$ уменьшилось время до постановки диагноза и на 47\% - денежные затраты [45].

\section{Рекомендация 1}

АТ-рТТГ являются чувствительным и специфическим тестом для диагностики и дифференциальной диагностики БГ

\section{$1, \varnothing \varnothing \varnothing \varnothing$}

\section{Рекомендация 2}

Если это технически возможно, во время беременности и в послеродовом периоде, а также при экстратиреоидной манифестации БГ может быть рекомендовано исследование, дифференцирующее стимулирующие и другие АТ-рТТГ

\section{$2, \varnothing \varnothing \varnothing \bigcirc$}

\section{ИНСТРУМЕНТАЛЬНЫЕ МЕТОДЫ ИССЛЕДОВАНИЯ}

Подходы к использованию различных методов диагностики БГ варьируют в разных странах. Помимо определения функции ЩЖ и АТ-рТТГ, большинство клиницистов предлагают проводить ультразвуковое исследование (УЗИ) ЩЖ и, несколько реже, сцинтиграфию. По данным опроса, в который вошли 263 эндокринолога и обсуждались 992 пациента, УзИ было рекомендовано опрошенными в 93,8\%, а сцинтиграфия - в 40,4\% случаев [46]. Крайне редко возникает необходимость в проведении компьютерной томографии (КТ), магнитно-резонансной томографии (МРТ) или позитронно-эмиссионной
КТ (ПЭТ-КТ). УЗИ - весьма информативно, неинвазивно и его можно быстро сделать уже при первичном обследовании пациента. Оно позволяет дополнить диагностическую информацию, выявить узловые образования и не несет лучевой нагрузки [47-49]. Результаты УзИ в значительной мере зависят от конкретного оборудования и от опыта специалиста, проводящего исследование. Рекомендуется использование высокочастотного линейного датчика. ЩЖ при БГ, по данным УЗИ, часто, но не всегда, характеризуется диффузным увеличением в сочетании с диффузным снижением эхогенности. При цветном допплеровском исследовании определяется усиление васкуляризации ЩЖ [50]. До назначения тиреостатиков при допплерографии для БГ в типичном случае характерен пульсирующий паттерн, который называют «пылающей щЖ» ("thyroid inferno"): множественные мелкие участки усиления интратиреоидного кровотока диффузно распределены в ЩЖ [51, 52]. Таких данных УЗИ в сочетании с повышенным уровнем АТ-рТТГ при типичной клинической картине вполне достаточно для постановки диагноза, и необходимости в проведении сцинтиграфии в этих случаях чаще нет. Она может понадобиться в сомнительных ситуациях, при наличии многоузлового зоба и перед проведением терапии ${ }^{131}$ I.

\section{Рекомендация 3}

Для подтверждения диагноза БГ рекомендуется проведение УзИ ЩЖ с анализом по серой шкале и цветным допплеровским исследованием

\section{$1, \varnothing \varnothing \varnothing \varnothing$}

\section{Рекомендация 4}

Сцинтиграфия ЩЖ рекомендуется при узловых образованиях в сочетании с тиреотоксикозом и перед назначением терапии ${ }^{131}$

\section{2, $\varnothing \varnothing \varnothing 0$}

\section{КОНСЕРВАТИВНОЕ ЛЕЧЕНИЕ}

Гипертиреоз при БГ лечится путем подавления синтеза тиреоидных гормонов при помощи тиреостатиков или путем редукции объема функционирующей тиреоидной ткани при тиреоидэктомии или терапии ${ }^{131} \mathrm{I}$. В европейских странах предпочтительным методом первичного лечения всегда была тиреостатическая терапия, и в последнее время она стала таковой в США и в странах Азии $[53,54]$. Чаще всего используются тионамиды пропилтиоурацил (ПТУ), карбимазол (КМЗ) и его активный метаболит - тиамазол (ТМ3, метимазол). КМ3 - неактивная субстанция, которая в печени декарбоксилируется, превращаясь в ТМЗ. Все тионамиды ингибируют конъюгацию йод-тиронинов молекулы тиреоглобулина (ТГ), в результате чего подавляется синтез тиреоидных гормонов [55]. Тионамиды подавляют работу тиреоидной пероксидазы (ТПО) и, вследствие этого - окисление и органификацию йодида (табл. 1).

Тиреостатики показаны в качестве первой линии терапии БГ, особенно у молодых пациентов, а также при коротком анамнезе тиреотоксикоза и в рамках подготовки к терапии радиоактивным йодом и к тиреоидэктомии $[2,6,22]$. Назначение тиреостатиков способствует снижению уровня АТ-рТТГ и повышению вероятности иммунологической ремиссии по сравнению с контрольной группой, не получавшей специфического лечения. 
Таблица 1. Механизм действия тиреостатиков

1. Интратиреоидное подавление:

- Окисления и органификации йода

- Конъюгация йодтирозинов

- Биосинтез тиреоглобулина

- Рост фолликулярных клеток

2. Подавление конверсии Т4/Т3 вне щитовидной железы (ПТУ)

ПТУ в высоких дозах ингибирует дейодирование $\mathrm{T}_{4}$ до $T_{3}$ [56]. Но этот эффект практически не имеет клинического значения (за исключением случаев лечения тяжелого тиреотоксикоза), поскольку ПТУ менее удобен для использования из-за меньшего периода полувыведения, чем у ТМЗ (табл. 2). Начальная доза ТМЗ обычно составляет 10-30 мг, в зависимости от тяжести заболевания, можно в один прием (КМ3 15-40 мг в день). ПтУ назначается исходно по 100 мг каждые 8 ч, при этом таким же образом, путем частых приемов, он принимается и дальше, на протяжении всего курса. Исходная доза постепенно уменьшается (титрационный режим) по мере ликвидации тиреотоксикоза. Оценка функции щЖ проводится через 3-4 недели после начала лечения, после чего доза титруется под контролем уровня св. $\mathrm{T}_{4}$ и $\mathrm{T}_{3}$. У большей части пациентов эутиреоз достигается через 3-4 недели лечения. Уровень ТТГ часто остается подавленным еще несколько месяцев и не является чувствительным параметром оценки раннего ответа на тиреостатическую терапию. При ведении терапии в титрационном режиме поддерживающая доза ТМ3 составляет 2,5-10 мг, а ПТУ - 50-100 мг. Альтернативой является лечение по схеме «блокируй и замещай», при котором ТМЗ в дозе 30 мг комбинируется c L-T $4^{\prime}$ что предотвращает развитие медикаментозного гипотиреоза на фоне относительно большой дозы тиреостатика. Первые сообщения о том, что на фоне терапии по схеме «блокируй и замещай» вероятность иммунологической ремиссии выше, не подтвердились $[2,57]$. В связи с этим титрационный режим более предпочтителен, поскольку позволяет минимизировать дозу тиреостатика.

Оптимальная продолжительность тиреостатической терапии в титрационном режиме составляет около 12-18 месяцев [57]. Более длительная терапия не несет дополнительных преимуществ в плане снижения вероятности рецидива тиреотоксикоза поле ее отмены [5, 57]. Максимальная вероятность иммунологической ремиссии (50-55\%) достигается именно через 12-18 месяцев терапии. Перед прекращением тиреостатической терапии рекомендуется определение уровня АТ-рТТГ, поскольку их низкий уровень свидетельствует о большей вероятности иммунологической ремиссии $[5,22]$. Такую же информацию несет определение в динамике уровня функциональных стимулирующих и блокирующих АТ-рТТГ [58, 59]. В отношении пациентов, у которых к концу 12-18-месячного курса тиреостатической терапии сохраняется высокий уровень АТ-рТТГ, в ряде случаев может быть принято решение о его продолжении еще на дополнительные 12 месяцев как альтернатива ${ }^{131}$ І или тиреоидэктомии. В отношении пролонгирования курса тиреостатической терапии у взрослых и детей опубликованы данные как «за», так и «против» [60-62]. Рецидив тиреотоксикоза чаще всего

Таблица 2. Фармакология и фармакокинетика тиреостатических препаратов

\begin{tabular}{|c|c|c|}
\hline Признак & Тиамазол & Пту \\
\hline Абсорбция & Быстрая & Быстрая \\
\hline Биодоступность & $\sim 100 \%$ & $\sim 100 \%$ \\
\hline Пик достижения плазменного уровня & 60-120 минут & 60 минут \\
\hline Период полужизни в плазме & $6-84$ & 90 минут \\
\hline Концентрация в ЩЖ & $5 \times 10^{5}$ моль/л & Неизвестна \\
\hline Обмен в ЩЖ & Низкий & Умеренный \\
\hline Длительность действия & $>244$ & $8-124$ \\
\hline Связывание с белками плазмы & Минимальное & $>75 \%$ \\
\hline Проникновение через плаценту & ++ & + \\
\hline Содержание в грудном молоке & ++ & + \\
\hline Объем распределения & 40 л & $20 \pi$ \\
\hline Экскреция & Почки & Почки \\
\hline $\begin{array}{l}\text { Метаболизм при тяжелой патологии: } \\
\text { • } \\
\text { • } \quad \text { почек } \\
\end{array}$ & $\begin{array}{l}\text { Не меняется } \\
\text { Замедляется }\end{array}$ & $\begin{array}{l}\text { Не меняется } \\
\text { Не меняется }\end{array}$ \\
\hline Относительная активность & $10 \times$ & $1 \times$ \\
\hline Нормализация $\mathrm{T}_{3} / \mathrm{T}_{4}$ & 6 недель & 12 недель \\
\hline Побочные эффекты & $15 \%$ & $20 \%$ \\
\hline Агранулоцитоз & $0,6 \%$ & $1-1,5 \%$ \\
\hline Перекрестное развитие побочных эффектов & $13,8 \%$ & $15,2 \%$ \\
\hline Приверженность лечению & Высокая & Ниже \\
\hline Стоимость & Низкая & Выше \\
\hline
\end{tabular}


развивается в течение первых 6-12 месяцев после отмены тиреостатиков. Это, как правило, происходит у пациентов с исходно тяжелым тиреотоксикозом, при сохранении высокого уровня АТ-рТТГ, но в индивидуальных случаях рецидив достаточно сложно предсказать. На протяжении первого года после отмены тиреостатиков пациентов необходимо часто обследовать, и делать это как минимум ежегодно в дальнейшем.

\section{Рекомендация 5}

Пациентам с впервые выявленной БГ целесообразно назначение тиреостатической терапия; по желанию пациента может быть назначена терапия ${ }^{131}$ I или выполнена тиреоидэктомия

\section{$1, \varnothing \varnothing \varnothing \varnothing$}

\section{Рекомендация 6}

Тиреостатическим препаратом выбора у всех пациентов с БГ, за исключением беременных женщин, является TM3 (KM3)

\section{$1, \varnothing \varnothing \varnothing \varnothing$}

\section{Рекомендация 7}

Если в качестве лечения был выбран курс тиреостатической терапии ТМ3, его рекомендуется проводить на протяжении 12-18 месяцев, после чего терапия отменяется, если уровень ТТГ в норме, а АТ-рТТГ не повышены

$1, \varnothing \varnothing \varnothing \varnothing$

\section{Рекомендация 8}

Перед прекращением терапии тиреостатиками рекомендуется определение уровня АТ-рТТГ, который является в этой ситуации предиктором иммунологической ремиссии заболевания $(1, \varnothing \varnothing \varnothing \varnothing)$

\section{Рекомендация 9}

Если спустя 12-18 месяцев тиреостатической терапии у пациента сохраняется повышенный уровень АТ-рТТГ, она в отдельных случаях может быть пролонгирована еще на 12 месяцев, или же принимается решение о радикальном лечении (терапия радиоактивным ${ }^{131}$ I, тиреоидэктомия)

$1, \varnothing \varnothing \varnothing \bigcirc$

\section{ПОБОЧНЫЕ ЭФФЕКТЫ ТИРЕОСТАТИКОВ}

Наиболее частыми (но относительно редко встречающимися) побочными эффектами тиреостатиков (1-5\%) являются кожный зуд, сыпь и артралгия (табл. 3). Минимальные кожные проявления могут корригироваться назначением антигистаминных препаратов без отмены тиреостатиков. В то же время сыпь и зуд могут самостоятельно проходить спонтанно или после перевода на другой тиреостатик [56]. При развитии тяжелой аллергической реакции перевод на альтернативный тиреостатик не рекомендуется. К крайне редким, но тяжелым побочным эффектам относятся гепатит [63], волчаночноподобный синдром и агранулоцитоз (число нейтрофилов менее 500/мл), развивающийся, по некоторым данным, в $0,1-1 \%$ случаев $[64,65]$. Агранулоцитоз несколько чаще развивается в течение первых 3 мес после начала тиреостатической терапии [65]. Кумулятивная распространенность агранулоцитоза, индуцированного тиреостатиками, и панцитопении на 100-й и 150-й день после начала ее приема составляет 0,28\% и 0,29\% соответственно [66]. Изучение генетических детерминант предрасположенности к развитию агранулоцитоза, индуцированного тиреостатиками, показало, что носительство аллелей HLA-B*38: 02 и HLA-DRB1*08: 03 является независимым фактором риска; в случае носительства обоих указанных аллелей отношение шансов развития агранулоцитоза увеличивается до 48,41 (95\% CI 21,66-108,22) [67]; у европейцев описана его ассоциация с аллелями HLA-B и NOX-3 $[68,69]$.

Тиамазол (КМЗ) и ПТУ обладают разной гепатотоксичностью. Гепатотоксичность ПтУ чаще проявляется у детей, тогда как ТМЗ чаще оказывается гепатотоксичным у взрослых, что клинически протекает менее тяжело, проявляясь холестазом [70]. В исследование, в которое вошли 71379 пациентов с впервые назначенной терапией тиреостатиками, было показано, что гепатотоксические и холестатические эффекты ТМЗ дозозависимы [71].

Таблица 3. Побочные эффекты тиреостатических препаратов

Побочный эффект

Процент встречаемости

\section{Частые}

- Кожный зуд

- Крапивница

- Артралгия, полиартрит

- Лихорадка

- Транзиторная легкая лейкопения

\section{Редкие}

- Диспепсия

- Нарушение вкуса и обоняния

- Агранулоцитоз

\section{Очень редкие}

- Апластическая анемия (ПТУ, КМЗ)

- Тромбоцитопения (ПТУ, КМЗ)

- Васкулит, волчаночноподобный синдром (ПТУ)

- Гепатит (ПТУ)

- Гипогликемия (антитела к инсулину, ПТУ)

- Холестатическая желтуха (KM3, ТМ3) 
При развитии тяжелых побочных эффектов тиреостатиков их необходимо отменить и повторно уже не возобновлять. Перед назначением тиреостатиков пациента желательно снабдить письменными инструкциями в отношении возможных симптомов агранулоцитоза (боль в горле, ангина, лихорадка, язвенное поражение глотки), при которых необходимо проведение общего анализа крови. Периодическое рутинное (скрининговое) проведение анализа крови с целью раннего выявления агранулоцитоза на фоне терапии тиреостатиками - неэффективно [56].

\section{Рекомендация 10}

Пациентов необходимо информировать о потенциально возможных побочных эффектах тиреостатических препаратов, а также о необходимости обращения к врачу в случае развития желтухи, осветления стула, потемнения мочи, повышения температуры тела, появления фарингита или цистита

\section{$1, \varnothing \varnothing \bigcirc \bigcirc$}

\section{Рекомендация 11}

Проведение общего анализа крови у пациентов, принимающих тиреостатики, необходимо при развитии лихорадочных заболеваний и/или фарингита; уровень печеночных ферментов определяется при развитии желтухи, осветления стула или потемнения мочи

$$
1, \varnothing \varnothing \bigcirc \bigcirc
$$

\section{ß-АДРЕНОБЛОКАТОРЫ ( $\beta$-АБ)}

Пропранолол (20-40 мг каждые 6 ч) или длительно действующие $\beta$-АБ (атенолол, бисопролол и др.) весьма эффективны для контроля адренергических симптомов, таких как дрожь, сердцебиения и тремор, особенно в начале лечения, когда тиреостатики еще не оказали свой эффект. Пропранолол в высоких дозах (40 мг 4 раза в день) подавляет периферическую конверсию $\mathrm{T}_{4}$ в $\mathrm{T}_{3}$. Кардиоселективные $\beta$-АБ имеют преимущества в плане предотвращения приступов фибрилляции предсердий и являются препаратами выбора для пациентов с бронхиальной астмой. Антикоагулянты, а именно варфарин или препараты прямого действия, показаны всем пациентам с мерцанием предсердий. При необходимости назначения дигоксина на фоне тиреотоксикоза может потребоваться использование больших доз препарата [2-6, 72].

\section{Рекомендация 12}

$\beta$-Адреноблокаторы рекомендуется назначать всем пациентам с тиреотоксикозом вследствие БГ, когда это приемлемо

\section{$1, \varnothing \varnothing \varnothing \varnothing$}

\section{РЕЦИДИВ ТИРЕОТОКСИКОЗА ПОСЛЕ ОТМЕНЫ ТИРЕОСТАТИКОВ}

По данным метаанализа [73], вероятность рецидива тиреотоксикоза после отмены тиреостатической терапии достаточно высока (52,7\%) и значительно превышает таковую после терапии ${ }^{131} \mathrm{I}(15 \%$, ОШ 6,25) и хирургического лечения (10\%, ОШ 9,09), при относительно немалой вероятности развития побочных эффектов (13\%). По данным другого метаанализа, включавшего суммарно 54 исследования и 7595 пациентов, вероятность рецидива тиреотоксикоза при БГ после отмены тиреостатиков составляет 49\% [74]. С рецидивом были ассоциированы такие факторы, как наличие сопутствующей ЭОП, курение, увеличенный объем ЩЖ, высокие уровни свободного $\mathrm{T}_{4}$, общего $\mathrm{T}_{3}$ и АТ-рТТГ. В проспективном исследовании использования полуколичественной шкалы GRAET рецидив тиреотоксикоза развился у $37 \%$ пациентов с БГ на протяжении 2 лет после отмены тиреостатиков [75]. Независимыми факторами риска рецидива оказались более молодой возраст, высокие уровни АТ-рТТГ и св. , $_{4^{\prime}}$ размер зоба, а также полиморфизм PTPN22 C/Т и подтипы DQB1*02, DQA1*05 и DRB1*03 HLA. С другой стороны, были продемонстрированы и определенные преимущества пролонгирования курса тиреостатической терапии еще на 12-24 месяца после рецидива тиреотоксикоза [76]. В этом исследовании сравнивалась аблативная терапии ${ }^{131}$ I и указанное пролонгирование курса TM3 (2,5-7 мг в день). По развитию побочных эффектов группы не отличались, тогда как временная нестабильность функции ЩЖ значимо чаще наблюдалась в группе, получившей терапию ${ }^{131}$. Обострение ЭОП, а также большая прибавка массы тела чаще наблюдаются после терапии ${ }^{131}$. По данным другого исследования, длительная терапия ТМЗ была признана безопасной, тогда как вероятность развития осложнений и затраты не превосходили таковые при терапии ${ }^{131} \mathrm{I}$ [77].

\section{Рекомендация 13}

Если после первого курса терапии тиреостатиками развивается рецидив тиреотоксикоза, рекомендуется радикальное лечение: терапия ${ }^{131}$ І или тиреоидэктомия. Продолжение терапии тиреостатиками также может быть одной из опций у пациентов, предпочитающих такой вариант лечения

$$
1, \varnothing \varnothing \varnothing \bigcirc
$$

\section{СУБКЛИНИЧЕСКИЙ ТИРЕОТОКСИКОЗ ПРИ БГ}

Эндогенный субклинический тиреотоксикоз (с уровнем ТТГ менее 0,1 мЕд/л) ассоциирован с повышенным риском смерти от ишемической болезни сердца (ИБС), развития фибрилляции предсердий, сердечной недостаточности и переломов костей, а также повышением общей смертности [78-82]. Кроме того, если субклинический тиреотоксикоз сочетается с носительством АТ-рТТГ, что свидетельствует о субклинической БГ, риск перехода субклинического тиреотоксикоза в манифестный на протяжении трех последующих лет составляет 30\% [83]. Несмотря на отсутствие данных рандомизированных исследований, по имеющимся рекомендациям, лечение субклинического тиреотоксикоза показано при стойком подавлении ТТГ ниже 0,1 мЕд/л у лиц старше 65 лет с целью предотвращения развития потенциально возможных осложнений и прогрессирования субклинического тиреотоксикоза до манифестного. Кроме того, лечение может быть рекомендовано пациентам старше 65 лет с уровнем ТТГ 0,1-0,39 мЕд/л, особенно при наличии факторов сердечно-сосудистого риска.

\section{Рекомендация 14}

Активное лечение при БГ, протекающей со стойким субклиническим тиреотоксикозом, рекомендуется у пациентов старше 65 лет и стойким подавлением ТТГ ниже $0,1 \mathrm{MEд/л}$

$1, \varnothing \varnothing \bigcirc \bigcirc$ 


\section{Рекомендация 15}

Методом выбора в лечении БГ, протекающей со стойким субклиническим тиреотоксикозом, является консервативная тиреостатическая терапия

\section{$1, \varnothing \varnothing \bigcirc \bigcirc$}

\section{ТИРЕОТОКСИЧЕСКИЙ КРИЗ}

Является очень редким острым осложнением БГ, со смертностью около 10\%, и требует быстрой диагностики и интенсивного лечения [84, 85]. Тиреотоксический криз (ТК) обычно манифестирует полиорганной недостаточностью, нарушением сознания, высокой температурой тела, сердечной недостаточностью, диареей и желтухой. К диагностическим критериям ТК у пациентов с тяжелым тиреотоксикозом при БГ следует отнести гиперпирексию, значительную тахикардию и аритмию, застойную сердечную недостаточность, ажитацию, делирий, психоз, ступор, кому, тошноту и рвоту, диарею, печеночную недостаточность [86]. В соответствии с балльной шкалой Burch-Wartofsky вероятность TK определяется как высокая при сумме баллов 25-44 и как низкая при сумме баллов симптомов и проявлений ниже 25. Национальное исследование, проведенное в Японии, выявило относительно большую, чем ожидалось, распространенность ТК и смертность при нем, что позволило широко рекомендовать использование следующей комбинированной схемы лечения: внутривенное введение ТМЗ или ПТУ (40-400 мг каждые 8 ч), глюкокортикоидов (метилпреднизолон 50 мг в/в), ß-блокаторов (пропранолол 40 мг каждые 6 ч) в условиях отделений интенсивной терапии [87]. Основными причинами смерти в результате TK являются: полиорганная недостаточность, сердечная и дыхательная недостаточность, аритмия, ДВС-синдром, перфорация ЖКТ, нарушение мозгового кровообращения и сепсис [88].

\section{Рекомендация 16}

Комплексное лечение тиреотоксического криза при БГ подразумевает терапию тиреостатиками, глюкокортикоидами, $\beta$-блокаторами, регидратацию, использование охлаждающих одеял, дыхательную поддержку и наблюдение в отделении интенсивной терапии

\section{$(1, \varnothing \varnothing \bigcirc \bigcirc)$}

\section{ТЕРАПИЯ РАДИОАКТИВНЫМ ЙОДОМ}

Терапия ${ }^{131}$ І используется при БГ с 1941 г., тем не менее на сегодняшний день опубликованы результаты лишь нескольких проспективных качественно организованных исследований, что оставляет вопросы в плане показаний, оптимальных доз, эффективности и побочных эффектов [89]. Клеточный эффект ионизирующей радиации заключается в повреждении генетического аппарата и смерти тироцитов. Повреждение ДНК под действием радиации является результатом комбинации прямых эффектов повреждения молекулярных связей и опосредованного образования свободных радикалов. В результате это приводит к снижению функции щЖ и уменьшению ее объема. В настоящее время не существует ни приемлемых в клинической практике методов оценки индивидуальной чувствительности к радиации, ни идеального метода оценки клинического прогноза в ответ на прием ${ }^{131} \mathrm{I}$.

\section{Показания ${ }^{131}$ | и его активности}

Потенциальными кандидатами на терапию ${ }^{131}$ I являются пациенты с побочными эффектами и с рецидивом тиреотоксикоза после курса тиреостатической терапии, а также пациенты с аритмиями сердца и тиреотоксическим периодическим параличом. Лишь в одном из опубликованных на сегодняшний день исследований три метода лечения БГ (тиреостатики, ${ }^{131}$ І и хирургическое лечение) сравнивались напрямую [90]. По данным этого исследования, риск рецидива тиреотоксикоза был закономерно максимален после курса тиреостатической терапии, а между ${ }^{131}$ и и хирургическим лечением его вероятность не отличалась. Данные о соотношении экономической эффективности различных методов лечения БГ весьма противоречивы [91-94]. Во многих центрах ${ }^{131}$ І назначается и детям с БГ, при этом в данном случае также рекомендуется использование аблативных активностей ${ }^{131}$ І с целью быстрого достижения стойкого гипотиреоза [95]. Терапия ${ }^{131}$ I противопоказана при беременности и грудном вскармливании, при этом зачатие не рекомендуется на протяжении минимум 6 месяцев после получения ${ }^{131}$. Каких-либо данных о том, что терапия радиоактивным йодом сопровождается отдаленными неблагоприятными последствиями на фертильность, риск выкидышей, врожденных аномалий и мертворождения, до настоящего времени нет [96]. Такой же шестимесячный период рекомендуется воздерживаться от зачатия и мужчинам, получившим ${ }^{131}$ I.

Принцип выбора активности ${ }^{131}$ I - ALARA (as low as reasonably achievable - англ. настолько малую, насколько это рационально возможно) - хорош для радионуклидной терапии в общем и целом, но попытка быстро избавиться от тиреотоксикоза и при этом максимально отсрочить или избежать развития гипотиреоза в случае с БГ — весьма иллюзорна. В этой связи большинство центров предпочитает использовать не некие расчеты, а стандартные активности, например, 185, 370 и 555 МБк, а выбор между ними базируется на клинических данных, в частности на объеме ЩЖ [89].

\section{Функция и объем ЩЖ на фоне терапии ${ }^{131}$}

Функция ЩЖ нормализуется с последующим развитием гипотиреоза у 50-90\% пациентов на протяжении 3-12 месяцев после назначения ${ }^{131}$ [ [89]. Пациента сразу следует проинформировать о том, что ему может понадобиться повторное назначение ${ }^{131} \mathrm{I}$. Вероятность развития гипотиреоза в общей массе пациентов с БГ составляет, по разным данным, от 5 до 50\% на протяжении 1 года после первого назначения ${ }^{131}$ I и положительно коррелирует с активностью ${ }^{131}$ I. В дальнейшем ежегодный прирост развития стойкого гипотиреоза составляет 3-5\% случаев, и он особо не зависит от исходной активности ${ }^{131}$ [ [97]. Даже назначение малых доз ${ }^{131}$, которое, как правило, сопровождается длительным периодом перманентного или рецидивирующего тиреотоксикоза, в конечном итоге чаще заканчивается развитием гипотиреоза [98]. Размер ЩЖ значительно уменьшается на протяжении 1 года после терапии ${ }^{131}$ I [97]. Терапия ${ }^{131}$ I не противопоказана при большом зобе, даже в случае его частичного ретростернального или интраторакального распространения. Терапия тиреостатиками должна быть как минимум временно приостановлена за одну неделю до и на протяжении первой недели после терапии ${ }^{131}$ [ [99]. 


\section{Неблагоприятные эффекты терапии ${ }^{131}$}

К ним могут быть отнесены боль и припухлость в области шеи и сиалоаденит. Сама по себе БГ при неадекватном лечении ассоциирована с повышенной соматической заболеваемостью и смертностью [100, 101], что не следует путать с неблагоприятными эффектами ${ }^{131} \mathrm{I}$. Компенсация тиреотоксикоза снижает смертность [102], при этом терапия ${ }^{131}$ I сама по себе не сопровождается ее повышением [89], а также повышением риска заболеваемости и/или смертности от рака ЩЖ [103].

Послеоперационный тиреотоксический криз встречается казуистически редко; если пациенты перед терапией ${ }^{131}$ I получали тиреостатики, уровень тиреоидных гормонов после введения радионуклида существенно не повышается и снижается спустя всего несколько дней [104]. Именно таким путем транзиторный тиреотоксикоз после терапии ${ }^{131}$ І и может быть предотвращен, но все-таки возникает у небольшой части пациентов, которые не возобновляют прием тиреостатиков [105]. Послеоперационное возобновление тиреотоксикоза чаще возникает при высоком уровне АТ-рТТГ. Транзиторный тиреотоксикоз сразу после назначения ${ }^{131}$ I сложно отличить от стойкого тиреотоксикоза вследствие назначения недостаточной дозы радионуклида. Последний вариант весьма вероятен, если тиреотоксикоз сохраняется спустя 3 месяца после назначения ${ }^{131}$ I. Гипотиреоз, развившийся в первые месяцы после назначения ${ }^{131} 1$, может быть транзиторным, а последний не всегда заканчивается стойким гипотиреозом; тем не менее заместительная терапия рекомендуется и при транзиторном гипотиреозе для предотвращения развития или усугубления ЭОП. Усугубление либо манифестация ЭОП после терапии ${ }^{131}$ І развиваются в $15-33 \%$ случаев [106]. Профилактический прием глюкокортикоидов может это предотвратить, но они никак не влияют на функцию ЩЖ и исход терапии ${ }^{131}$ I [107].

\section{Рекомендация 17}

Абсолютные показания к терапии ${ }^{131}$ І как методу лечения тиреотоксикоза при БГ отсутствуют, но чаще всего ${ }^{131}$ І рекомендуется пациентам с побочными эффектами от тиреостатической терапии или при рецидиве тиреотоксикоза после ее длительного использования

\section{$(1, \varnothing \varnothing \bigcirc \bigcirc)$}

\section{Рекомендация 18}

Пациента необходимо ознакомить со всеми преимуществами и потенциальными эффектами терапии ${ }^{131} \mathrm{I}$, включая побочные, и получить его информированное согласие

$$
(1, \varnothing \varnothing \bigcirc \bigcirc)
$$

\section{Рекомендация 19}

Если перед терапией ${ }^{131}$, пациентам назначаются тиреостатики, их следует отменить на одну неделю до и минимум на одну после приема ${ }^{131}$, чтобы не снизить его эффективность

\section{$(1, \varnothing \varnothing \varnothing \varnothing)$}

\section{Рекомендация 20}

Никакие дозиметрические расчеты не позволяют определить активность ${ }^{131}$ І так, чтобы в отдаленном периоде у пациента сохранялся стойкий эутиреоз, в связи с чем вполне приемлемо назначение пациентам с БГ стандартных аблативных активностей ${ }^{131}$ I

\section{$(1, \varnothing \varnothing \varnothing О)$}

\section{Рекомендация 21}

Беременность и грудное вскармливание являются абсолютными противопоказаниями к терапии ${ }^{131}$ |

$$
(1, \varnothing \varnothing \varnothing \bigcirc)
$$

\section{Рекомендация 22}

Зачатие необходимо отложить на период не менее 6 месяцев после терапии ${ }^{131}$ I как у женщин, так и у мужчин

$(1, \varnothing \varnothing \varnothing \bigcirc)$

\section{Рекомендация 23}

При планировании терапии ${ }^{131}$ І у детей с БГ им должна быть назначена активность ${ }^{131} \mathrm{I}$, обеспечивающая достижение быстрого и стойкого гипотиреоза

$$
(1, \varnothing \varnothing \bigcirc \bigcirc)
$$

\section{ХИРУРГИЧЕСКОЕ ЛЕЧЕНИЕ}

Тиреоидэктомия редко рассматривается как лечение первого выбора при впервые диагностированной БГ. По данным недавних опросов американских и европейских врачей, тиреоидэктомию как первый метод лечения БГ предпочли соответственно 0,9\% [108] и 2,1\% [22] опрошенных. Тем не менее тиреоидэктомия - весьма эффективна и рациональна при большом зобе, при сопутствующем первичном гиперпаратиреозе или раке ЩЖ, при развитии побочных эффектов тиреостатиков, она лишена лучевого воздействия [109] и зачастую единственно рациональна при отсутствии в распоряжении врачей терапии ${ }^{131}$ [ [2]. Относительные преимущества и недостатки тиреоидэктомии приведены в табл. 4.

Так или иначе, тиреоидэктомия - дорогостоящее инвазивное лечение, требующее госпитализации и несущее определенные риски анестезиологического пособия и самого оперативного вмешательства. По определению, как и в случае терапии ${ }^{131} \mathrm{I}$, тиреоидэктомия приводит к необходимости пожизненной заместительной терапии L-T.

Таблица 4. Преимущества и недостатки тиреоидэктомии при болезни Грейвса

- Невозможен рецидив тиреотоксикоза

- Отсутствует радиоактивное облучение

- Быстрейшая дефинитивная ликвидация тиреотоксикоза и излечение

- Отсутствие влияния на течение эОП
- Риск послеоперационного гипопаратиреоза

- Риск повреждения возвратного гортанного нерва

- Риск, связанный с анестезией и хирургическим вмешательством

- Необходимость госпитализации

- Высокая себестоимость

- Рубец на шее 
Если выбрано хирургическое лечение, то проведение операций другого объема, в частности частичных резекций ЩЖ, в настоящее время не рекомендуется, поскольку они в ближайшей или отдаленной перспективе все равно заканчиваются гипотиреозом, но могут привести к развитию рецидива тиреотоксикоза, что делает результат частичных резекций щЖ непрогнозируемым [110, 111]. Поскольку однократное назначение ${ }^{131}$ I все-таки не всегда заканчивается развитием гипотиреоза, тиреоидэктомия, опять же, по определению, является более радикальным методом лечения, что и обусловило противоречивые результаты двух систематических обзоров, один из которых показал преимущества тиреоидэктомии над ${ }^{131}$ I [110], а другой не увидел разницы между результатами использования этих двух методов [73].

Для минимизации специфического операционного риска (гипопаратиреоз, повреждение возвратных гортанных нервов) тиреоидэктомия должна выполняться хирургом, имеющим достаточный опыт проведения именно этой операции (high-volume surgeon) [112]. Перед тиреоидэктомией по поводу БГ необходимо достижение эутиреоидного состояния на фоне приема тиреостатиков [109]. Использование насыщенных растворов йодида калия (пламерунг) может использоваться непосредственно перед оперативным вмешательством (10 дней) для уменьшения васкуляризации и снижения кровопотери во время операции [113]. В настоящее время растворы йода в подготовке к тиреоидэктомии рекомендуют менее 40\% тиреоидологов [22]. Для снижения риска послеоперационной гипокальциемии перед операцией рекомендуется компенсировать дефицит витамина D [114].

\section{Рекомендация 24}

Если в качестве метода лечения БГ выбрана хирургическая операция - оптимальным объемом является тиреоидэктомия, при этом ее следует проводить опытному хирургу, имеющему большой опыт проведения тиреоидэктомий с большим ежегодным числом таких операций

\section{$(1, \varnothing \varnothing \varnothing \varnothing)$}

\section{Рекомендация 25}

Операцию следует проводить после того, как у пациента достигнуто эутиреоидное состояние на фоне приема тиреостатиков

\section{$(1, \varnothing \varnothing \varnothing \varnothing)$}

\section{Рекомендация 26}

Перед тиреоидэктомией целесообразна коррекция дефицита витамина $D$, что снижает риск развития послеоперационной гипокальциемии

$$
(1, \varnothing \varnothing \varnothing \varnothing)
$$

\section{Рекомендация 27}

Для подготовки к операции (в течение 10 дней перед ней) может использоваться назначение растворов йодида калия

\section{$(2, \varnothing \varnothing \varnothing \bigcirc)$}

\section{ЛЕЧЕНИЕ ТИРЕОТОКСИКОЗА ВСЛЕДСТВИЕ БГ У ПАЦИЕНТОВ С СОПУТСТВУЮЩЕЙ ОРБИТОПАТИЕЙ}

Нарушение функции ЩЖ, как гипотиреоз, так и тиреотоксикоз, могут оказать неблагоприятное влияние на течение ЭОП. В соответствии с рекомендациями ЕTA/ EUGOGO [115] и итальянским консенсусом [116] первой задачей лечения пациента с БГ и ЭОП является достижение стойкого эутиреоза. Выбор метода лечения патологии ЩЖ при наличии ЭОП может представить определенные сложности [117]. Тиреостатические препараты сами по себе не влияют на естественное течение ЭОП, но косвенно, за счет того, что восстанавливают эутиреоз, могут оказать позитивный эффект и на процесс в орбите $[118,119]$. Гипотиреоз может косвенно способствовать прогрессированию ЭОП. Терапия ${ }^{131}$ І способствует прогрессированию предсуществующей ЭОП или ее возникновению de novo [119, 121, 122], особенно у курильщиков, у пациентов с уже имеющейся [119] и недавно развившейся ЭОП, а также при несвоевременной коррекции гипотиреоза в исходе ${ }^{131}$ I $[125,126]$ и при высоком уровне АТ-рТТГ [127].

С целью профилактики развития и прогрессирования ЭОП у пациентов высокого риска эффективно использование таблетированных глюкокортикоидов (ГК) в небольших дозах $[115,128]$, как это было показано в двух рандомизированных клинических исследованиях (РКИ) $[119,121]$ и двух метаанализах $[129,130]$. В стероидной профилактике нет необходимости у пациентов при отсутствии или при неактивной ЭОП, а также если у них нет факторов риска ее развития [115, 130]. Тиреоидэктомия, вероятно, не влияет на течение ЭОП [122, 131] (табл. 5). Выбор метода лечения тиреотоксикоза определяется двумя факторами: тяжестью и активностью ЭОП.

\section{Легкая и неактивная эоП}

У таких пациентов выбор метода лечения тиреотоксикоза не зависит от изменений со стороны глаз и определяется факторами, связанными с ЩЖ и самим пациентом [116, 117]. Если выбрана терапия ${ }^{131} \mathrm{I}$, глюкостероидная профилактика не показана, за исключением случаев, когда есть очевидные факторы риска развития и прогресси-

Таблица 5. Влияние различных методов лечения тиреотоксикоза при болезни Грейвса на течение сопутствующей эндокринной офтальмопатии

\begin{tabular}{lcc}
\hline \multicolumn{1}{c}{ Степень тяжести и активности эОП } & Тиреостатики & Тиреоидэктомия \\
Легкая и неактивная & + & ${ }^{131}$ \\
Легкая и активная & $+^{2}$ & + \\
Умеренная-тяжелая и неактивная & + & $+{ }^{3}$ \\
Умеренная-тяжелая и активная & + \\
Угроза зрению & + & - \\
\hline
\end{tabular}

${ }^{1}$ глюкостероидная профилактика по показаниям

${ }^{2}$ назначение селена сроком на 6 месяцев

${ }^{3}$ глюкостероидная профилактика

(«+»- рекомендуется; «—»- предпочтительно не использовать (не рекомендуется) 
рования ЭОП [115]. Может быть показана пластическая хирургия по косметическим показаниям.

\section{Легкая и активная эоп}

Выбор метода лечения тиреотоксикоза, как правило, не зависит от изменений со стороны глаз [2]. Данные РКИ, которые бы свидетельствовали о том, что при такой ЭОП отдаленный прогноз лучше в случае длительного приема тиреостатиков по сравнению с радикальным лечением, отсутствуют. Стероидная профилактика показана в том случае, если как метод лечения тиреотоксикоза выбрана терапия ${ }^{131}$ I [130]. В том случае, если выбрана длительная тиреостатическая терапия, 6-месячное назначение препаратов селена улучшает прогноз и препятствует прогрессированию легкой и активной ЭОП [132].

\section{ЭОП от умеренной до тяжелой, неактивная}

Выбор метода лечения тиреотоксикоза, как правило, также не зависит от ЭОП. Если он падает на ${ }^{131} \mathrm{I}$, то при отсутствии других факторов реактивации процесса в орбите стероидную профилактику можно не проводить [117].

\section{ЭОП от умеренной до тяжелой, активная}

Необходима быстрая коррекция тиреотоксикоза тиреостатиками, и это само по себе может оказать позитивный эффект на течение ЭОП $[60,61,115]$. Радикальное лечение является альтернативным вариантом [133]. Активную ЭОП необходимо лечить специфически.

\section{ЭОП, угрожающая зрению}

Тиреотоксикоз должен быть максимально быстро ликвидирован тиреостатиками, и пациенту сразу должны быть назначено внутривенное введение глюкокортикоидов в высоких дозах, а при отсутствии эффекта в течение 2-4 недель - показана декомпрессия орбиты [115].

\section{Рекомендация 28}

У пациентов с ЭОП необходимо быстрое достижение стабильного эутиреоидного состояния на фоне терапии тиреостатиками

$(1, \varnothing \varnothing \varnothing \varnothing)$

\section{Рекомендация 29}

Пациентам, которым планируется терапия ${ }^{131}$ I, стероидная профилактика показана при легкой и активной предсуществующей ЭОП, а также при наличии других факторов риска ее прогрессирования

$(1, \varnothing \varnothing \varnothing \varnothing)$

\section{Рекомендация 30}

При наличии активной ЭОП от умеренной до тяжелой, именно ЭОП должна быть приоритетна при выборе метода лечения тиреотоксикоза. Необходимо быстрое достижение и поддержание стойкого эутиреоза

$(1, \varnothing \varnothing \varnothing \varnothing)$

\section{Рекомендация 31}

У пациентов с ЭОП, угрожающей зрению, тиреотоксикоз рекомендуется лечить тиреостатическими препаратами

\section{$(1, \varnothing \varnothing \bigcirc \bigcirc)$}

\section{Рекомендация 32}

Выбор метода лечения тиреотоксикоза при БГ и неактивной ЭОП осуществляется независимо от изменений со стороны глаз

$(1, \varnothing \varnothing \bigcirc \bigcirc)$

\section{БЕРЕМЕННОСТЬ И ПОСЛЕРОДОВЫЙ ПЕРИОД}

\section{Женщины, планирующие беременность}

Выбор метода лечения БГ зависит от пожеланий пациентки, анамнеза, уровня АТ-рТТГ и времени планирования зачатия [134-138]. Беременность следует отложить, если у пациентки неадекватно и нестабильно контролируется гиперфункция ЩЖ, что необходимо оценить дважды с интервалом около 2 месяцев на одной и той же терапии. Женщин необходимо проинформировать о следующем.

1. Существует небольшое повышение риска развития врожденных пороков, если во время беременности назначаются тиреостатики.

2. Возможность отмены тиреостатиков на протяжении 6-10-й недели беременности.

3. Преимуществах ПТУ, если тиреостатик необходимо назначать перед наступлением или на протяжении І триместра беременности.

4. Целесообразности смены ПтУ на ТМЗ после 16-й недели беременности.

5. Противопоказаниях к использованию режима «блокируй и замещай».

Беременность необходимо отложить на 6 месяцев после назначения терапии ${ }^{131} \mathrm{I}$, и на это время рекомендуется использование надежной контрацепции. В том случае если в качестве лечения БГ выбрана тиреоидэктомия, после нее беременность может планироваться сразу после достижения эутиреоза на фоне заместительной терапии $\mathrm{L}_{4}$.

Рекомендация 33

Женщин репродуктивного возраста с БГ необходимо поставить в известность о необходимости контроля функции ЩЖ и достижения стабильного эутиреоидного состояния перед планированием беременности

\section{$1, \varnothing \varnothing \bigcirc \bigcirc$}

\section{Рекомендация 34}

При подтверждении наступления беременности у женщины с БГ ей необходимо срочно проконсультироваться с лечащим врачом (эндокринологом)

\section{$1, \varnothing \varnothing \varnothing \varnothing$}

\section{Рекомендация 35}

Если у женщины, получающей по поводу БГ ТМЗ, наступает беременность, ее на протяжении I триместра целесообразно перевести на ПТУ

\section{$1, \varnothing \varnothing \varnothing \varnothing$}

\section{Беременность и БГ}

Исходная доза тиреостатика при БГ во время беременности зависит от тяжести тиреотоксикоза: TM3 5-15 мг, КМ3 10-30 мг или ПТУ 50-200 мг [139, 140]. Эмбриопатия, индуцированная ТМЗ (КМЗ), к которой относят дисморфный внешний вид, аплазию кожи, атрезию хоан или пищевода, дефекты брюшной стенки, умбиликоцеле, дефекты межжелудочковой перегородки, развивается у 2-4\% детей, матери которых получали TM3 во время беременности, особенно на протяжение первых 6-10 недель [137, 141]. Вероятность развития врожденных дефектов при приеме беременными Пту такая же, но спектр этих дефектов менее тяжел и чаще всего представлен кистами лица и шеи, а также аномалиями мочевых путей у мальчиков [142]. 
Для лечения тиреотоксикоза во время беременности может использоваться пропранолол (10-40 мг, 3-4 раза в день), тогда как $\beta$-блокаторов длительного действия следует избегать, поскольку их прием может способствовать задержке роста и брадикардии у плода, а также неонатальной гипогликемии [143]. Тиреоидэктомия как метод лечения БГ во время беременности может рассматриваться в случае развития тяжелых аллергических реакций или абсолютных противопоказаний к терапии тиреостатиками [136, 144].

При отсутствии АТ-рТТГ вероятность рецидива тиреотоксикоза на протяжении последующих 8 недель после отмены тиреостатиков составляет всего около 5\% [145]. В случае наступления беременности у женщины, получающей тиреостатики, если ремиссия БГ по данным обследований вполне вероятна, препарат может быть отменен, а функцию ЩЖ следует оценивать на протяжении I триместра каждые 2 недели. Если при этом сохраняется эутиреоз, гормональные исследования следует проводить 1 раз в месяц на протяжении II-III триместров. Вероятность рецидива тиреотоксикоза при отмене тиреостатиков достаточно высока, если до этого пациентка их принимала менее 6 месяцев, при высокой потребности в препарате для поддержания эутиреоза, при низком или подавленном уровне ТТГ на фоне терапии, а также при высоком уровне АТ-рТТГ и при наличии ЭОП [146, 147].

Уровень св. $\mathrm{T}_{4}$ (или общ. $\mathrm{T}_{4}$ ) следует поддерживать на верхнем пределе специфического для беременных референсного диапазона [148]. К III триместру на этом основании тиреостатики у многих женщин могут быть отменены вследствие исчезновения АТ-рТТГ $[135,136]$.

При значительном повышении уровня АТ-рТТГ (более чем 3-кратное) на поздних сроках беременности в дальнейшем понадобится обследование новорожденного на предмет транзиторного неонатального нарушения функции ЩЖ [149-151]. В соответствии со всем сказанным определение уровня АТ-рТТГ необходимо всем беременным женщинам на ранних сроках беременности, а если они повышены - повторно на 18-22-й неделе; исследование проводится или при помощи чувствительного метода конкурентного связывания, или путем функционального исследования в культуре клеток [5, 21-23, $43,44,149,150]$. Лечение транзиторного фетального (неонатального) гипертиреоза, вызванного материнскими АТ-рТТГ, подразумевает назначение ТМ3, $\beta$-блокаторов и кардиотропной терапии [43].

\section{Рекомендация 36}

У всех беременных женщин с аутоиммунной патологией ЩЖ в анамнезе рекомендуется определение уровня АТ-рТТГ при помощи чувствительных методов конкурентного связывания или функциональных методов на культурах клеток; исследование проводится на ранних сроках беременности, а в случае повышения уровня АТ-рТТГ - повторно на 18-22-й неделе беременности

\section{$1, \varnothing \varnothing \varnothing \varnothing$}

\section{Рекомендация 37}

При сохранении высокого уровня АТ-рТТГ (>3 раз выше верхнего референса) рекомендуется оценка состояния ЩЖ у плода и новорожденного

$1, \varnothing \varnothing \varnothing \varnothing$

\section{Рекомендация 38}

При лечении беременных женщин с БГ рекомендуется назначение минимально необходимых доз тиреостатиков, при этом их назначение в режиме «блокируй и замещай» противопоказано

\section{$1, \varnothing \varnothing \varnothing \varnothing$}

\section{Рекомендация 39}

Определение уровня св. $\mathrm{T}_{4}$ (общего $\mathrm{T}_{4}$ ) и ТТГ у беременных женщин рекомендуется каждые 2 недели после инициации тиреостатической терапии и каждые 4 недели после достижения поддерживающей дозы

\section{$1, \varnothing \varnothing \bigcirc \bigcirc$}

\section{Рекомендация 40}

Переход с приема ПТУ на ТМЗ рекомендуется, если потребность в назначении тиреостатика сохраняется после 16 недель беременности

\section{$1, \varnothing 0 \bigcirc \bigcirc$}

\section{Рекомендация 41}

Если женщина получает малые дозы ТМ3 (<5-10 мг) или ПТУ (<50-100 мг), то при наступлении беременности тиреостатики могут быть отменены до срока 6-10 недель

\section{$2, \varnothing 000$}

\section{Послеродовый период}

Своего пика риск рецидива БГ достигает через 7-9 месяцев после родов (ОР 3,8), что было показано в исследованиях на датской и японских популяциях $[135,152]$. Тиреостатики проникают в грудное молоко в очень небольших количествах, и относительно малые дозы ПТУ (<250 мг) или ТМ3 (<20 мг) безопасны как для матери, так и для грудного ребенка. Принимать тиреостатики женщине рекомендуется после кормления, раздробив суточную дозу на несколько приемов $[153,154]$.

\section{Рекомендация 42}

Принципы лечения БГ у кормящих женщин не отличаются от стандартных

\section{$1, \varnothing \varnothing \bigcirc \bigcirc$ \\ Рекомендация 43}

С учетом данных о большей гепатотоксичности Пту во время беременности рекомендуется назначение TM3

\section{$1, \varnothing \varnothing \bigcirc \bigcirc$}

\section{ПОЖИЛЫЕ ПАЦИЕНТЫ, ДЕТИ И ПОДРОСТКИ}

\section{Пожилые пациенты}

Заболеваемость БГ в пожилом возрасте значительно снижается, тем не менее ее развитие возможно и после 80-90 лет. Типичные симптомы тиреотоксикоза, такие как похудение, тремор, ажитация, могут присутствовать, тем не менее зачастую у пожилых людей клиническая картина не столь яркая и представлена лишь общей слабостью, тревожностью, одышкой («апатический тиреотоксикоз»). У пожилых чаще встречаются такие осложнения тиреотоксикоза, как фибрилляция предсердий, застойная сердечная недостаточность, стенокардия, инфаркт миокарда. Общие принципы лечения тиреотоксикоза у пожилых не отличаются от таковых у молодых пациентов, и оно должно начинаться с приема тиреостатиков и достижения эутиреоидного состояния, как правило, в сочетании с назначением $\beta$-адреноблокаторов. 
При наличии тяжелых сердечно-сосудистых осложнений, таких как фибрилляция предсердий и сердечная недостаточность, целесообразно в ближайшие сроки использовать радикальное лечение, обычно терапию ${ }^{131} \mathrm{I}$, чтобы в дальнейшем исключить саму возможность развития тиреотоксикоза с фатальными осложнениями. У пациентов старческого возраста, особенно у малоподвижных, при менее тяжелом тиреотоксикозе может быть приемлемым длительное назначение небольших доз тиреостатиков (ТМ3 2,5-5 мг), особенно при недоступности ${ }^{131}$ I и противопоказаниях к хирургическому лечению. У пациентов пожилого возраста несколько чаще встречается индуцированный тиреостатиками агранулоцитоз [155], о возможных признаках которого обязательно предупредить пациента или, при наличии у него когнитивных нарушений, - его родственников. Кроме того, у пожилых пациентов чаще развиваются осложнения тяжелой ЭОП [156], в связи с чем нужно иметь в виду необходимость прекращения курения и избегания развития гипотиреоза.

\section{Рекомендация 44}

Пожилым пациентам с тяжелыми осложнениями тиреотоксикоза, такими, как фибрилляция предсердий, сердечная недостаточность, декомпенсация ИБС, показано радикальное лечение, в большинстве случаев ${ }^{131}$ ।

\section{$1, \varnothing \varnothing \varnothing \bigcirc$}

\section{Рекомендация 45}

Длительная терапия ТМ3 может быть рекомендована как один из методов лечения пожилых пациентов с легким течением БГ

\section{$2, \varnothing 000$}

\section{Дети и подростки}

У детей и тинэйджеров БГ часто диагностируется запоздало, поскольку такие симптомы, как ухудшение успеваемости, изменения поведения, тревожность, нарушения сна с трудом позволяют заподозрить заболевание. Его легко просмотреть у девочек-подростков с потерей массы тела, сочтя ее связанной с нарушениями пищевого поведения. Вероятность ремиссии на фоне длительной тиреостатической терапии у детей и подростков значительно меньше, чем у взрослых пациентов; она спустя 2 года лечения не превышает 25\% [157, 158], в связи с этим, если и рассчитывать на ремиссию БГ у детей, то тиреостатическая терапия у них должна продолжаться значительно дольше. Кроме того, у детей чаще встречаются побочные эффекты тиреостатиков, в связи с чем ПТУ не рекомендуется для использования у детей, поскольку, по имеющимся данным, риск развития токсической печеночной недостаточности составляет 1 случай на 2000 детей, принимавших ПТУ [159]. При развитии у детей тяжелых побочных эффектов на тиреостатики в большинстве случаев рекомендуется проведение тиреоидэктомии. В последние годы появились убедительные данные, свидетельствующие о безопасности терапии ${ }^{131} \mathrm{I}$ у детей постпубертатного возраста [160]. Так или иначе, у детей и подростков после длительной терапии тиреостатиками в малых дозах проводится тиреоидэктомия или терапия ${ }^{131}$ I (в возрасте старше 16 лет). При принятии решения о выборе метода лечения БГ в этой группе следует помнить о том, что любые эпизоды тиреотоксикоза или гипотиреоза могут отразиться на успеваемости пациента.

\section{Рекомендация 46}

Детям и подросткам следует избегать назначения ПтУ $1, \varnothing \varnothing \varnothing \varnothing$

\section{Рекомендация 47}

Длительная тиреостатическая терапия тиамазолом является основным методом лечения БГ у детей

\section{$1, \varnothing \varnothing \varnothing \bigcirc$}

\section{Рекомендация 48}

Методом выбора радикального лечения у детей следует признать тиреоидэктомию, тем не менее в постпубертатном возрасте с этой целью может быть назначен ${ }^{131}$ I

\section{$2, \varnothing \varnothing 00$}

\section{СИНДРОМ ИММУННОГО ВОССТАНОВЛЕНИЯ (СИВ)}

Впервые развитие БГ на фоне СИВ было описано у двух пациентов с рассеянным склерозом, которые получали алемтузумаб [161]. Такое лечение исходно вызывает лимфопению, но спустя 12-24 месяца в 20-30\% случаев приводит к развитию БГ с повышением уровня АТ-рТТГ на фоне восстановления числа лейкоцитов. Аналогичным образом БГ может развиваться у пациентов с ВИЧ, успешно получавших высокодозированную антиретровирусную терапию: БГ манифестирует на фоне восстановления числа CD4-лимфоцитов [162]. Синдром иммунного восстановления также описан у пациентов после трансплантации костного мозга. В большинстве случаев тиреотоксикоз весьма эффективно купируется тиреостатиками, и его развитие, в зависимости от клинической ситуации, не является показанием для прекращения иммуномодулирующей терапии. Хотя первые публикации на эту тему обычно делали вывод, что по поводу БГ таким пациентам предпочтительно радикальное лечение, дальнейший опыт показал, что подход к такой индуцированной БГ может ничем не отличаться от лечения спонтанно манифестировавшего заболевания [163]. Более того, иммунологический «инсульт» в этой ситуации может иметь транзиторный характер, поэтому вполне оправданным вариантом лечения как раз может быть назначение тиреостатиков до тех пор, пока не перестанут определяться АТ-рТТГ.

\section{Рекомендация 49}

Развитие БГ на фоне иммунотропной терапии различных заболеваний не является показанием для ее прекращения, как и не является обязательным проведение в этой ситуации радикального лечения БГ

\section{$1, \varnothing 0 \bigcirc \bigcirc$}

\section{Рекомендация 50}

При развитии БГ в рамках синдрома иммунного восстановления длительность тиреостатической терапии может определяться продолжительностью циркуляции AT-рTTГ

\section{$2, \varnothing 000$}

\section{ЗАКЛЮЧЕНИЕ}

В представленные клинические рекомендации пока не вошли результаты работ, изучавших эффективность новых лекарственных препаратов, направленных на модификацию естественного течения БГ путем попыток воздействия на ее патогенез. К таким препаратам 
относятся моноклональные АТ-рТТГ [164], иммуномодулирующие пептиды, связывающиеся с рТТГ, малые молекулы-лиганды рТТГ [165], которые блокируют тиреоидстимулирующий эффект АТ-рТТГ, то есть являются антагонистами АТ-рТТГ. Данные об их эффективности пока весьма предварительны и пока непонятно, могут ли они использоваться для постоянного приема. Достаточные данные о целесообразности применения биологической терапии, например, ритуксимабом, получены не были [166].

В настоящее время оптимальное лечение БГ определяется предпочтением пациента и индивидуальным сочетанием таких факторов, как возраст, наличие сопутствующих нарушений ритма сердца или ИБС, размер зоба и тяжесть тиреотоксикоза. У каждого метода лечения есть свои ограничения и потенциальные побочные эффекты, которые должны быть хорошо известны врачам, предлагающим выбор метода лечения БГ.

Целевой аудиторией для этих рекомендаций являются клиницисты, которые непосредственно занимаются лечением БГ. В документе представлены принципы рационального выбора терапии, которые не могут заменить клинического опыта, необходимости принятия индивидуального решения в конкретных ситуациях, с учетом пожеланий самого пациента и его семьи. Анализировать каждую рекомендацию необходимо именно с этой точки зрения. Если это возможно, лечение пациентов следует проводить в специализированных центрах.

\section{СПИСОК ЛИТЕРАТУРЫ | REFERENCES}

1. Bahn RS, Burch HB, Cooper DS, et al. Hyperthyroidism and other causes of thyrotoxicosis: management guidelines of the American Thyroid Association and American Association of Clinical Endocrinologists. Endocr Pract. 2011;17(3):456-520. Doi: 10.4158/ep.17.3.456.

2. Bartalena L. Diagnosis and management of Graves' disease: a global overview. Nat Rev Endocrinol. 2013;9(12):724-734. Doi: 10.1038/nrendo.2013.193.

3. Kahaly GJ, Dillmann WH. Thyroid hormone action in the heart. Endocr Rev. 2005;26(5):704-728. Doi: 10.1210/er.2003-0033.

4. Biondi B, Kahaly GJ. Cardiovascular involvement in patients with different causes of hyperthyroidism. Nat Rev Endocrinol. 2010;6(8):431-443. Doi: 10.1038/nrendo.2010.105.

5. Ross DS, Burch HB, Cooper DS, et al. 2016 American Thyroid Association guidelines for diagnosis and management of hyperthyroidism and other causes of thyrotoxicosis. Thyroid. 2016:26(10):1343-1421. Doi: 10.1089/thy.2016.0229.

6. Smith TJ, Hegedus L. Graves' disease. N Engl J Med. 2016:375(16):1552-1565. Doi: 10.1056/NEJMra1510030.

7. Nystrom HF, Jansson S, Berg G. Incidence rate and clinical features of hyperthyroidism in a long-term iodine sufficient area of Sweden (Gothenburg) 2003-2005. Clin Endocrinol. 2013;78(5):768-776. Doi: $10.1111 /$ cen.12060.

8. McLeod DS, Caturegli P, Cooper DS, et al. Variation in rates of autoimmune thyroid disease by race/ethnicity in US military personnel. JAMA. 2014;311(15):1563-1565 Doi: 10.1001/jama.2013.285606.

9. Rapoport B, Chazenbalk GD, Jaume JC, MCLachlan SM. The thyrotropin (TSH) receptor: interaction with TSH and autoantibodies. Endocr Rev. 1998:19(6):673-716. Doi: 10.1210/edrv.19.6.0352.

10. Rapoport B, McLachlan SM. TSH receptor cleavage into subunits and shedding of the A-subunit; a molecular and clinical perspective. Endocr Rev. 2016;37(2):114-134. Doi: 10.1210/er.2015-1098.

11. Smith TJ, Hegedus L, Douglas RS. Role of insulin-like growth factor-1 (IGF-1) pathway in the pathogenesis of Graves' orbitopathy. Best Pract Res Clin Endocrinol Metab. 2012;26(3):291-302. Doi: 10.1016/j.beem.2011.10.002

12. Brix TH, Kyvik KO, Christensen K, Hegedus L. Evidence for a major role of heredity in Graves' disease: a population-based study of two Danish twin cohorts. J Clin Endocrinol Metab. 2001;86(2):930-934. Doi: 10.1210/jcem.86.2.7242

13. Inaba H, De Groot LJ, Akamizu T. Thyrotropin receptor epitope and human leukocyte antigen in Graves' disease. Front Endocrinol (Lausanne). 2016;7:120. Doi: 10.3389/fendo.2016.00120.

14. Lee HJ, Li CW, Hammerstad SS, et al. Immunogenetics of autoimmune thyroid diseases: a comprehensive review. J Autoimmun. 2015;64:82-90. Doi: 10.1016/j.jaut.2015.07.009.

15. Strieder TG, Prummel MF, Tijssen JG, et al. Risk factors for and prevalence of thyroid disorders in a cross-sectional study among healthy female relatives of patients with autoimmune thyroid disease. Clin Endocrinol (Oxf). 2003;59(3):396-401. Doi: 10.1046/j.1365-2265.2003.01862.x.

16. Laurberg P, Pedersen KM, Vestergaard H, Sigurdsson $G$ High incidence of multinodular toxic goitre in the elderly population in a low iodine intake area vs. high incidence of Graves' disease in the young in a high iodine intake area: comparative surveys of thyrotoxicosis epidemiology in EastJutland Denmark and Iceland. J Intern Med. 1991;229(5):415-420. Doi: 10.1111/j.1365-2796.1991.tb00368.x.

17. Brix TH, Hansen PS, Kyvik KO, Hegedus L. Cigarette smoking and risk of clinically overt thyroid disease: a population-based twin case-control study. Arch Intern Med. 2000;160(5):661-666. Doi: 10.1001/archinte.160.5.661.

18. Swiglo BA, Murad MH, Schunemann HJ, et al. A case for clarity, consistency, and helpfulness: state-of-the-art clinical practice guidelines in endocrinology using the grading of recommendations, assessment, development, and evaluation system. J Clin Endocrinol Metab. 2008;93(3):666-673. Doi: 10.1210/jc.2007-1907.

19. de los Santos ET, Starich GH, Mazzaferri EL. Sensitivity, specificity, and cost-effectiveness of the sensitive thyrotropin assay in the diagnosis of thyroid disease in ambulatory patients. Arch Intern Med. 1989;149(3):526-532. Doi: 10.1001/archinte.149.3.526.

20. Spencer CA, LoPresti JS, Patel A, et al. Applications of a new chemiluminometric thyrotropin assay to subnormal measurement. J Clin Endocrinol Metab. 1990;70(2):453-460. Doi: 10.1210/jcem-70-2-453.

21. Grebe SK, Kahaly GJ. Laboratory testing in hyperthyroidism. Am J Med. 2012;125(9):S2. Doi: 10.1016/j.amjmed.2012.05.013.

22. Bartalena L, Burch HB, Burman KD, Kahaly GJ. A 2013 European survey of clinical practice patterns in the management of Graves' disease. Clin Endocrinol. 2016;84(1):115-120. Doi: 10.1111/cen.12688.

23. Kahaly GJ, Olivo PD. Graves' disease. N Engl J Med. 2017;376(2):184 Doi: 10.1056/NEJMc1614624.

24. Kahaly GJ, Diana T. TSH receptor antibody functionality and nomenclature. Front Endocrinol (Lausanne). 2017;8:28. Doi: 10.3389/fendo.2017.00028.

25. Tozzoli R, Bagnasco M, Giavarina D, Bizzaro N. TSH receptor autoantibody immunoassay in patients with Graves' disease: improvement of diagnostic accuracy over different generations of methods: systematic review and meta-analysis. Autoimmun Rev. 2012;12(2):107-113. Doi: 10.1016/j.autrev.2012.07.003.

26. Kahaly GJ. Bioassays for TSH receptor antibodies: quo vadis? Eur Thyroid J. 2015;4(1):3-5. Doi: 10.1159/000375445.

27. Araki N, lida M, Amino N, et al. Rapid bioassay for detection of thyroid-stimulating antibodies using cyclic adenosine monophosphate-gated calcium channel and aequorin Eur Thyroid J. 2015;4(1):14-19. Doi: 10.1159/000371740.

28. Lytton SD, Kahaly GJ. Bioassays for TSH-receptor autoantibodies: an update. Autoimmun Rev. 2010;10(2):116-122. Doi: 10.1016/j.autrev.2010.08.018

29. Lytton SD, LiY, Olivo PD, et al. Novel chimeric thyroidstimulating hormone-receptor bioassay for thyroid-stimulating immunoglobulins. Clin Exp Immunol. 2010;162(3):438-446. Doi: 10.1111/j.1365-2249.2010.04266.x.

30. Li Y, Kim J, Diana T, et al. A novel bioassay for anti-thyrotrophin receptor autoantibodies detects both thyroid-blocking and stimulating activity. Clin Exp Immunol. 2013;173(3):390-397. Doi: $10.1111 /$ cei.12129. 
31. Diana T, Kanitz M, Lehmann M, et al. Standardization of a bioassay for thyrotropin receptor stimulating autoantibodies. Thyroid. 2015;25(2):169-175. Doi: 10.1089/thy.2014.0346.

32. Diana T, Li Y, Olivo PD, et al. Analytical performance and validation of a bioassay for thyroidblocking antibodies. Thyroid. 2016;26(5):734-740. Doi: 10.1089/thy.2015.0447.

33. Diana T, Krause J, Olivo PD, et al. Prevalence and clinical relevance of thyroid stimulating hormone receptor-blocking antibodies in autoimmune thyroid disease. Clin Exp Immunol. 2017;189(3):304-309. Doi: 10.1111/cei.12980.

34. Diana T, Wuster C, Kanitz M, Kahaly GJ. Highly variable sensitivity of five binding and two bio-assays for TSH-receptor antibodies. J Endocrinol Invest. 2016;39(10):1159-1165. Doi: 10.1007/s40618-016-0478-9.

35. Diana T, Wüster C, Olivo PD, et al. Performance and specificity of six immunoassays for TSH receptor antibodies: a multicenter study. Eur Thyroid J. 2017;6(5):243-249. Doi: 10.1159/000478522.

36. Lytton SD, Ponto KA, Kanitz M, et al. A novel thyroid stimulating immunoglobulin bioassay is a functional indicator of activity and severity of Graves' orbitopathy. J Clin Endocrinol Metab. 2010;95(5):2123-2131. Doi: 10.1210/jc.2009-2470.

37. Ponto KA, Kanitz M, Olivo PD, et al. Clinical relevance of thyroidstimulating immunoglobulins in graves' ophthalmopathy. Ophthalmology. 2011;118(11):2279-2285. Doi: 10.1016/j.ophtha.2011.03.030.

38. Ponto KA, Diana T, Binder $\mathrm{H}$, et al. Thyroid-stimulating immunoglobulins indicate the onset of dysthyroid optic neuropathy. J Endocrinol Invest. 2015;38(7):769-777. Doi: 10.1007/s40618-015-0254-2.

39. Kahaly GJ, Diana T, Glang J, et al. Thyroid stimulating antibodies are highly prevalent in Hashimoto's thyroiditis and associated orbitopathy. J Clin Endocrinol Metab. 2016;101(5):1998-2004. Doi: 10.1210/jc.2016-1220.

40. Diana T, Brown RS, Bossowski A, et al. Clinical relevance of thyroid-stimulating autoantibodies in pediatric Graves' disease a multicenter study. J Clin Endocrinol Metab. 2014;99(5):1648-1655. Doi: 10.1210/jc.2013-4026.

41. Kampmann E, Diana T, Kanitz M, et al. Thyroid stimulating but not blocking autoantibodies are highly prevalent in severe and active thyroid-associated orbitopathy: a prospective study. Int J Endocrinol. 2015;2015:678194. Doi: 10.1155/2015/678194.

42. Stozek K, Bossowski A, Ziora K, et al. Functional TSH receptor antibodies in children with autoimmune thyroid diseases. Autoimmunity. 2018;51(2):62-68. Doi: 10.1080/08916934.2018.1431776.

43. Kiefer FW, Klebermass-Schrehof K, Steiner M, et al. Fetal/neonatal thyrotoxicosis in a newborn from a hypothyroid woman with Hashimoto thyroiditis. J Clin Endocrinol Metab. 2017;102(1):6-9. Doi: 10.1210/jc.2016-2999.

44. Mestman JH. Fetal hyperthyroidism resulted from TSI in a mother with Hashimoto's hypothyroidism. Clin Thyroidol. 2017;29(1):32-34 Doi: 10.1089/ct.2017;29.32-34.

45. McKee A, Peyerl F. TSI assay utilization: impact on costs of Graves' hyperthyroidism diagnosis. Am J Manag Care. 2012;18(1):e1-14.

46. Goichot B, Bouee S, Castello-Bridoux C, Caron P. Survey of clinical practice patterns in the management of 992 hyperthyroid patients in France. Eur Thyroid J. 2017;6(3):152-159. Doi: 10.1159/000453260.

47. Kahaly GJ, Bartalena L, Hegedus L. The American Thyroid Association/American Association of Clinical Endocrinologists guidelines for hyperthyroidism and other causes of thyrotoxicosis: a European perspective. Thyroid. 2011;21(6):585-591. Doi: 10.1089/thy.2011.2106.ed3.

48. Hegedus L. Thyroid ultrasound. Endocrinol Metab Clin North Am. 2001;30(2):339-360. Doi: 10.1016/s0889-8529(05)70190-0.

49. Vitti P, Rago T, Mancusi F, et al. Thyroid hypoechogenic pattern at ultrasonography as a tool for predicting recurrence of hyperthyroidism after medical treatment in patients with Graves' disease. Acta Endocrinol (Copenh). 1992;126(2):128-131. Doi: 10.1530/acta.0.1260128.

50. Erdogan MF, Anil C, Cesur M, et al. Color flow Doppler sonography for the etiologic diagnosis of hyperthyroidism. Thyroid. 2007;17(3):223-228. Doi: 10.1089/thy.2006.0104.

51. Ralls PW, Mayekawa DS, Lee KP, et al. Color-flow Doppler sonography in Graves' disease: "thyroid inferno". AJR Am J Roentgenol. 1988;150(4):781-784. Doi: 10.2214/ajr.150.4.781.
52. Kim TK, Lee EJ. The value of the mean peak systolic velocity of the superior thyroidal artery in the differential diagnosis of thyrotoxicosis. Ultrasonography. 2015;34(4):292-296. Doi: 10.14366/usg.14059.

53. Emiliano AB, Governale L, Parks M, Cooper DS. Shifts in propylthiouracil and methimazole prescribing practices: antithyroid drug use in the United States from 1991 to 2008. J Clin Endocrinol Metab. 2010;95(5):2227-2233. Doi: 10.1210/jc.2009-2752.

54. Brito JP, Schilz S, Singh Ospina N, et al. Antithyroid drugs - the most common treatment for Graves' disease in the United States: a nationwide population-based study. Thyroid. 2016;26(8):1144-1145. Doi: 10.1089/thy.2016.0222.

55. Cooper DS. Antithyroid drugs in the management of patients with Graves' disease: an evidence-based approach to therapeutic controversies. J Clin Endocrinol Metab. 2003;88(8):3474-3481. Doi: 10.1210/jc.2003-030185.

56. Cooper DS. Antithyroid drugs. N Engl J Med. 2005;352(9):905-917. Doi: 10.1056/NEJMra042972.

57. Abraham P, Avenell A, McGeoch SC, et al. Antithyroid drug regimen for treating Graves' hyperthyroidism. Cochrane Database Syst Rev. 2010;2010:CD003420. Doi: 10.1002/14651858.CD003420.pub4.

58. Leschik JJ, Diana T, Olivo PD, et al. Analytical performance and clinical utility of a bioassay for thyroid-stimulating immunoglobulins. Am J Clin Pathol. 2013;139(2):192-200. Doi: 10.1309/AJCPZUT7CNUEU7OP.

59. Giuliani C, Cerrone D, Harii N, et al. A TSHR-LH/CGR chimera that measures functional thyroid-stimulating autoantibodies (TSAb) can predict remission or recurrence in Graves' patients undergoing antithyroid drug (ATD) treatment. J Clin Endocrinol Metab. 2012;97(7):E1080-E1087. Doi: 10.1210/jc.2011-2897.

60. Laurberg P, Berman DC, Andersen S, Bulow Pedersen I. Sustained control of Graves' hyperthyroidism during long-term low-dose antithyroid drug therapy of patients with severe Graves' orbitopathy. Thyroid. 2011;21(9):951-956. Doi: 10.1089/thy.2011.0039.

61. Elbers L, Mourits M, Wiersinga W. Outcome of very long-term treatment with antithyroid drugs in Graves' hyperthyroidism associated with Graves' orbitopathy. Thyroid. 2011;21(3):279-283. Doi: 10.1089/thy.2010.0181.

62. Leger J, Carel JC. Management of endocrine disease: arguments for the prolonged use of antithyroid drugs in children with Graves' disease. Eur J Endocrinol. 2017;177(2):R59-R67. Doi: 10.1530/EJE-16-0938.

63. Pearce $\mathrm{SH}$. Spontaneous reporting of adverse reactions to carbimazole and propylthiouracil in the UK. Clin Endocrinol (Oxf). 2004;61(5):589-594. Doi: 10.1111/j.1365-2265.2004.02135.x.

64. Yang J, Zhu YJ, Zhong JJ, et al. Characteristics of antithyroid drug-induced agranulocytosis in patients with hyperthyroidism: a retrospective analysis of 114 cases in a single institution in China involving 9690 patients referred for radioiodine treatment over 15 years. Thyroid. 2016;26(5):627-633. Doi: 10.1089/thy.2015.0439.

65. Nakamura H, Miyauchi A, Miyawaki N, Imagawa J. Analysis of 754 cases of antithyroid drug-induced agranulocytosis over 30 years in Japan. J Clin Endocrinol Metab. 2013;98(12):4776-4783. Doi: 10.1210/jc.2013-2569.

66. Watanabe N, Narimatsu H, Noh JY, et al. Antithyroid druginduced hematopoietic damage: a retrospective cohort study of agranulocytosis and pancytopenia involving 50,385 patients with Graves' disease. J Clin Endocrinol Metab. 2012;97(1):E49-E53. Doi: 10.1210/jc.2011-2221.

67. Chen PL, Shih SR, Wang PW, et al. Genetic determinants of antithyroid drug-induced agranulocytosis by human leukocyte antigen genotyping and genome-wide association study. Nat Commun. 2015;6:7633. Doi: 10.1038/ncomms8633.

68. Hallberg P, Eriksson N, Ibanez L, et al. Genetic variants associated with antithyroid drug-induced agranulocytosis: a genome-wide association study in a European population. Lancet Diabetes Endocrinol. 2016;4(6):507-516. Doi: 10.1016/S2213-8587(16)00113-3.

69. Plantinga TS, Arts P, Knarren GH, et al. Rare NOX3 variants confer susceptibility to agranulocytosis during thyrostatic treatment of Graves' disease. Clin Pharmacol Ther. 2017;102(6):1017-1024 Doi: 10.1002/cpt.733.

70. Rivkees SA, Mattison DR. Ending propylthiouracilinduced liver failure in children. N Engl J Med. 2009:360(15):1574-1575. Doi: 10.1056/NEJMc0809750.

71. Wang MT, Lee WJ, Huang TY, et al. Antithyroid drugrelated hepatotoxicity in hyperthyroidism patients: a population-based cohort study. Br J Clin Pharmacol. 2014;78(3):619-629. Doi: 10.1111/bcp.12336. 
72. Castro MR, Espiritu RP, Bahn RS, et al. Predictors of malignancy in patients with cytologically suspicious thyroid nodules. Thyroid. 2011;21(11):1191-1198. Doi: 10.1089/thy.2011.0146.

73. Sundaresh V, Brito JP, Wang Z, et al. Comparative effectiveness of therapies for Graves' hyperthyroidism: a systematic review and network meta-analysis. J Clin Endocrinol Metab. 2013;98(9):3671-3677. Doi: 10.1210/jc.2013-1954.

74. Struja T, Fehlberg H, Kutz A, et al. Can we predict relapse in Graves' disease? Results from a systematic review and meta-analysis. Eur J Endocrinol. 2017;176(1):87-97. Doi: 10.1530/EJE-16-0725.

75. Vos $X G$, Endert $E, Z$ winderman $A H$, et al. Predicting the risk of recurrence before the start of antithyroid drug therapy in patients with Graves' hyperthyroidism. J Clin Endocrinol Metab. 2016;101(4):1381-1389. Doi: 10.1210/jc.2015-3644.

76. Villagelin D, Romaldini JH, Santos RB, et al. Outcomes in relapsed Graves' disease patients following radioiodine or prolonged low dose of methimazole treatment. Thyroid. 2015;25(12):1282-1290. Doi: 10.1089/thy.2015.0195.

77. Azizi F, Ataie L, Hedayati M, et al. Effect of long-term continuous methimazole treatment of hyperthyroidism: comparison with radioiodine. Eur J Endocrinol. 2005:152(5):695-701. Doi: 10.1530/eje.1.01904.

78. Biondi B, Bartalena L, Cooper DS, et al. The 2015 European Thyroid Association guidelines on diagnosis and treatment of endogenous subclinical hyperthyroidism. Eur Thyroid J. 2015;4(3):149-163. Doi: 10.1159/000438750.

79. Collet TH, Gussekloo J, Bauer DC, et al. Thyroid Studies Collaboration: Subclinical hyperthyroidism and the risk of coronary heart disease and mortality. Arch Intern Med. 2012;172(10):799-809. Doi: 10.1001/archinternmed.2012.402.

80. Gencer B, Collet TH, Virgini V, et al. Subclinical thyroid dysfunction and the risk of heart failure events: an individual participant data analysis from 6 prospective cohorts. Circulation. 2012;126(9):1040-1049. Doi: 10.1161/CIRCULATIONAHA.112.096024.

81. Wirth CD, Blum MR, da Costa BR, et al. Subclinical thyroid dysfunction and the risk for fractures: a systematic review and meta-analysis. Ann Intern Med. 2014;161(3):189-199. Doi: 10.7326/M14-0125.

82. Blum MR, Bauer DC, Collet TH, et al. Subclinical thyroid dysfunction and fracture risk: a meta-analysis. JAMA. 2015;313(20):20552065. Doi: 10.1001/jama.2015.5161.

83. Zhyzhneuskaya S, Addison C, Tsatlidis V, et al. The natural history of subclinical hyperthyroidism in Graves' disease: the rule of thirds. Thyroid. 2016;26(6):765-769. Doi: 10.1089/thy.2015.0470.

84. Satoh T, Isozaki O, Suzuki A, et al. 2016 guidelines for the management of thyroid storm from the Japan Thyroid Association and Japan Endocrine Society. Endocr J. 2016;63(12):1025-1064. Doi: 10.1507/endocrj.EJ16-0336.

85. Akamizu T. Thyroid storm: a Japanese perspective. Thyroid. 2018;28(1):32-40. Doi: 10.1089/thy.2017.0243.

86. Burch HB, Wartofsky L. Life-threatening thyrotoxicosis: thyroid storm. Endocrinol Metab Clin North Am. 1993;22(2):263-277.

87. Akamizu T, Satoh T, Isozaki O, et al. Japan Thyroid Association: Diagnostic criteria, clinical features, and incidence of thyroid storm based on nationwide surveys. Thyroid. 2012;22(7):661-679. Doi: $10.1089 /$ thy.2011.0334

88. Isozaki O, Satoh T, Wakino S, et al. Treatment and management of thyroid storm: analysis of the nationwide surveys: the taskforce committee of the Japan Thyroid Association and Japan Endocrine Society for the establishment of diagnostic criteria and nationwide surveys for thyroid storm. Clin Endocrinol. 2016;84(6):912-918. Doi: 10.1111/cen.12949.

89. Bonnema SJ, Hegedus L. Radioiodine therapy in benign thyroid diseases: effects, side effects, and factors affecting therapeutic outcome. Endocr Rev. 2012;33(6):920-980. Doi: 10.1210/er.2012-1030.

90. Torring O, Tallstedt L, Wallin G, et al. Graves' hyperthyroidism: treatment with antithyroid drugs, surgery, or radioiodine a prospective, randomized study. J Clin Endocrinol Metab. 1996;81(8):2986-2993. Doi: 10.1210/jcem.81.8.8768863.

91. In H, Pearce EN, Wong AK, et al. Treatment options for Graves' disease: a cost-effectiveness analysis. J Am Coll Surg. 2009;209(2):170-179. Doi: 10.1016/j.jamcollsurg.2009.03.025.

92. Zanocco K, Heller M, Elaraj D, Sturgeon C. Is subtotal thyroidectomy a cost-effective treatment for Graves' disease? A cost-effectiveness analysis of the medical and surgical treatment options. Surgery. 2012;152(2):164-172. Doi: 10.1016/j.surg.2012.02.020.
93. Patel NN, Abraham P, Buscombe J, Vanderpump MP. The cost effectiveness of treatment modalities for thyrotoxicosis in a UK center. Thyroid. 2006;16(6):593-598. Doi: 10.1089/thy.2006.16.593.

94. Donovan PJ, McLeod DS, Little R, Gordon L. Cost-utility analysis comparing radioactive iodine, anti-thyroid drugs and total thyroidectomy for primary treatment of Graves' disease. Eur J Endocrinol. 2016;175(6):595-603. Doi: 10.1530/EJE-16-0527.

95. Cohen RZ, Felner El, Heiss KF, et al. Outcomes analysis of radioactive iodine and total thyroidectomy for pediatric Graves' disease. J Pediatr Endocrinol Metab. 2016;29(3):319-325. Doi: 10.1515/jpem-2015-0333.

96. Sawka AM, Lakra DC, Lea J, et al. A systematic review examining the effects of therapeutic radioactive iodine on ovarian function and future pregnancy in female thyroid cancer survivors. Clin Endocrinol (Oxf). 2008;69(3):479-490. Doi: 10.1111/j.1365-2265.2008.03222.x.

97. Nygaard B, Hegedus L, Gervil M, et al. Influence of compensated radioiodine therapy on thyroid volume and incidence of hypothyroidism in Graves' disease. J Intern Med. 1995;238(6):491-497. Doi: 10.1111/j.1365-2796.1995.tb01230.x.

98. Sridama V, McCormick M, Kaplan EL, et al. Long-term follow-up study of compensated low-dose 131I therapy for Graves' disease. N Engl J Med. 1984;311(7):426-432. Doi: 10.1056/NEJM198408163110702.

99. Walter MA, Briel M, Christ-Crain M, et al. Effects of antithyroid drugs on radioiodine treatment: systematic review and metaanalysis of randomised controlled trials. BMJ. 2007;334(7592):514. Doi: 10.1136/bmj.39114.670150.BE.

100. Brandt F, Thvilum M, Almind D, et al. Graves' disease and toxic nodular goiter are both associated with increased mortality but differ with respect to the cause of death: a Danish population-based register study. Thyroid. 2013;23(4):408-413. Doi: 10.1089/thy.2012.0500.

101. Schwensen CF, Brandt F, Hegedus L, Brix TH. Mortality in Graves' orbitopathy is increased and influenced by gender, age and pre-existing morbidity: a nationwide Danish register study. Eur J Endocrinol. 2017;176(6):669-676. Doi: 10.1530/EJE-16-0954.

102. Lillevang-Johansen M, Abrahamsen $B$, Jorgensen HL, et al. Excess mortality in treated and untreated hyperthyroidism is related to cumulative periods of low serum TSH. J Clin Endocrinol Metab. 2017;102(7):2301-2309. Doi: 10.1210/jc.2017-00166.

103. Ron E, Doody MM, Becker DV, et al. Cancer mortality following treatment for adult hyperthyroidism. Cooperative Thyrotoxicosis Therapy Follow-up Study Group. JAMA. 1998;280(4):347355. Doi: 10.1001/jama.280.4.347.

104. Bonnema SJ, Bennedbaek FN, Veje A, et al. Propylthiouracil before 131 therapy of hyperthyroid diseases: effect on cure rate evaluated by a randomized clinical trial. J Clin Endocrinol Metab. 2004;89(9):4439-4444. Doi: 10.1210/jc.2004-0247.

105. Bonnema SJ, Bennedbaek FN, Gram J, et al. Resumption of methimazole after 131I therapy of hyperthyroid diseases: effect on thyroid function and volume evaluated by a randomized clinical trial. Eur J Endocrinol. 2003;149(6):485-492. Doi: 10.1530/eje.0.1490485.

106. Bartalena L, Marcocci C, Bogazzi F, et al. Use of corticosteroids to prevent progression of Graves' ophthalmopathy after radioiodine therapy for hyperthyroidism. N Engl J Med. 1989;321(20):1349-1352. Doi: 10.1056/NEJM198911163212001.

107. Jensen BE, Bonnema SJ, Hegedus L. Glucocorticoids do not influence the effect of radioiodine therapy in Graves' disease. Eur J Endocrinol. 2005;153(1):15-21. Doi: 10.1530/eje.1.01924.

108. Burch HB, Burman KD, Cooper DS. A 2011 survey of clinical practice patterns in the management of Graves' disease. J Clin Endocrinol Metab. 2012;97(12):4549-4558. Doi: 10.1210/jc.2012-2802.

109. Bartalena L, Chiovato L, Vitti P. Management of hyperthyroidism due to Graves' disease: frequently asked questions and answers (if any). J Endocrinol Invest. 2016;39(10):1105-1114. Doi: 10.1007/s40618-016-0505-x.

110. Genovese BM, Noureldine SI, Gleeson EM, et al. What is the best definitive treatment for Graves' disease? A systematic review of the existing literature. Ann Surg Oncol. 2013;20(2):660667. Doi: 10.1245/s10434-012-2606-x.

111. Guo Z, Yu P, Liu Z, et al. Total thyroidectomy vs bilateral subtotal thyroidectomy in patients with Graves' diseases: a meta-analysis of randomized clinical trials. Clin Endocrinol (Oxf). 2013;79(5):739-746. Doi: 10.1111/cen.12209.

112. Sosa JA, Bowman HM, Tielsch JM, et al. The importance of surgeon experience for clinical and economic outcomes from thyroidectomy. Ann Surg. 2008;228(3):320-330. Doi: 10.1097/00000658-199809000-00005. 
113. Erbil Y, Ozluk Y, Giris M, et al. Effect of lugol solution on thyroid gland blood flow and microvessel density in the patients with Graves' disease. J Clin Endocrinol Metab. 2007;92(6):2182-2189. Doi: 10.1210/jc.2007-0229.

114. Edafe O, Antakia R, Laskar N, et al. Systematic review and metaanalysis of predictors of post-thyroidectomy hypocalcaemia. Br J Surg. 2014;101(4):307-320. Doi: 10.1002/bjs.9384.

115. Bartalena L, Baldeschi L, Boboridis K, et al. European Group on Graves Orbitopathy: The 2016 European Thyroid Association/European Group on Graves' Orbitopathy guidelines for the management of Graves' orbitopathy. Eur Thyroid J. 2016;5(1):9-26. Doi: 10.1159/000443828.

116. Bartalena L, Macchia PE, Marcocci C, et al. Effects of treatment modalities for Graves' hyperthyroidism on Graves' orbitopathy: a 2015 Italian Society of Endocrinology Consensus Statement. J Endocrinol Invest. 2015;38(4):481-487. Doi: 10.1007/s40618-015-0257-z.

117. Bartalena L. The dilemma of how to manage Graves' hyperthyroidism in patients with associated orbitopathy. J Clin Endocrinol Metab. 2011;96(3):592-599. Doi: 10.1210/jc.2010-2329.

118. Laurberg P, Wallin G, Tallstedt L, et al. TSH-receptor autoimmunity in Graves' disease after therapy with anti-thyroid drugs, surgery, or radioiodine: a 5-year prospective randomized study. Eur J Endocrinol. 2008;158(1):69-75. Doi: 10.1530/EJE-07-0450.

119. Bartalena L, Marcocci C, Bogazzi F, et al. Relation between therapy for hyperthyroidism and the course of Graves' ophthalmopathy. N Engl J Med. 1998;338(2):73-78. Doi: 10.1056/NEJM199801083380201.

120. Karlsson F, Dahlberg P, Jansson R, et al. Importance of TSH receptor activation in the development of severe endocrine ophthalmopathy. Acta Endocrinol. 1989;121(suppl 2):132-141.

121. Bartalena L, Marcocci C, Bogazzi F, et al. Use of corticosteroids to prevent progression of Graves' ophthalmopathy after radioiodine therapy for hyperthyroidism. N Engl J Med. 1989;321(20):1349-1352. Doi: 10.1056/NEJM198911163212001.

122. Tallstedt L, Lundell G, Torring O, et al. Occurrence of ophthalmopathy after treatment for Graves' hyperthyroidism. The Thyroid Study Group. N Eng/ J Med. 1992;326(26):1733-1738. Doi: 10.1056/NEJM199206253262603.

123. Traisk F, Tallstedt $L$, Abraham-Nordling M, et al. Thyroid-associated ophthalmopathy after treatment for Graves' hyperthyroidism with antithyroid drugs or iodine-131. J Clin Endocrinol Metab. 2009;94:3700-3707.

124. Vannucchi G, Campi I, Covelli C, et al. Graves' orbitopathy activation after radioactive iodine therapy with and without steroid prophylaxis. J Clin Endocrinol Metab. 2009;94(9):3381-3386. Doi: 10.1210/jc.2009-0506.

125. Tallstedt L, Lundell G, Blomgren $\mathrm{H}$, Bring J. Does early administration of thyroxine reduce the development of Graves' ophthalmopathy after radioiodine treatment? Eur J Endocrinol. 1994;130(5):494-497. Doi: 10.1530/eje.0.1300494

126. Perros $P$, Kendall-Taylor P, Neoh C, et al. A prospective study of the effects of radioiodine therapy for hyperthyroidism in patients with minimally active Graves' ophthalmopathy. J Clin Endocrinol Metab. 2005:90(9):5321-5323. Doi: 10.1210/jc.2005-0507.

127. Kung AW, Yau CC, Cheng A. The incidence of ophthalmopathy after radioiodine therapy for Graves' disease: prognostic factors and the role of methimazole. J Clin Endocrinol Metab. 1994;79(2):542-546. Doi: 10.1210/jcem.79.2.7913934.

128. Lai A, Sassi L, Compri E, et al. Lower dose prednisone prevents radioiodine-associated exacerbation of initially mild or absent Graves' orbitopathy: a retrospective cohort study. J Clin Endocrinol Metab. 2010;95(3):1333-1337. Doi: 10.1210/jc.2009-2130.

129. Acharya SH, Avenell A, Philip S, et al. Radioiodine therapy (RAI) for Graves' disease (GD) and the effect on ophthalmopathy: a systematic review. Clin Endocrinol (Oxf). 2008;69(6):943-950. Doi: 10.1111/j.1365-2265.2008.03279.x.

130. Shiber S, Stiebel-Kalish H, Shimon I, et al. Glucocorticoid regimens for prevention of Graves' ophthalmopathy progression following radioiodine treatment: systematic review and meta-analysis. Thyroid. 2014;24(10):1515-1523. Doi: 10.1089/thy.2014.0218.

131. Marcocci C, Bruno-Bossio G, Manetti L, et al. The course of Graves' ophthalmopathy is not influenced by near-total thyroidectomy: a case-control study. Clin Endocrinol. 1999;51 (4):503-508. Doi: 10.1046/j.1365-2265.1999.00843.x.

132. Marcocci C, Kahaly GJ, Krassas GE, et al. Selenium and the course of mild Graves' orbitopathy. N Engl J Med. 2011;364(20):1920-1931. Doi: 10.1056/NEJMoa1012985.
133. Bartalena L, Tanda ML. Clinical practice: Graves'ophthalmopathy. N Eng/ J Med. 2009;360(10):994-1001. Doi: 10.1056/NEJMcp0806317.

134. Krassas GE, Poppe K, Glinoer D. Thyroid function and human reproductive health. Endocr Rev. 2010;31(5):702-755. Doi: 10.1210/er.2009-0041.

135. Andersen SL, Olsen J, Carle A, Laurberg P. Hyperthyroidism incidence fluctuates widely in and around pregnancy and is at variance with some other autoimmune diseases: a Danish population-based study. J Clin Endocrinol Metab. 2015;100(3):1164-1171. Doi: 10.1210/jc.2014-3588.

136. Laurberg P, Bournaud C, Karmisholt J, Orgiazzi J. Management of Graves' hyperthyroidism in pregnancy: focus on both maternal and foetal thyroid function, and caution against surgical thyroidectomy in pregnancy. Eur J Endocrinol. 2009;160(1):1-8. Doi: 10.1530/EJE-08-0663.

137. Andersen SL, Olsen J, Laurberg P. Antithyroid drug side effects in the population and in pregnancy. J Clin Endocrinol Metab. 2016;101(4):1606-1614. Doi: 10.1210/jc.2015-4274.

138. Alexander EK, Larsen PR. High dose of 1311 therapy for the treatment of hyperthyroidism caused by Graves' disease. J Clin Endocrinol Metab. 2002;87(3):1073-1077. Doi: 10.1210/jcem.87.3.8333.

139. Nicholas WC, Fischer RG, Stevenson RA, Bass JD. Single daily dose of methimazole compared to every 8 hours propylthiouracil in the treatment of hyperthyroidism. South Med J. 1995;88(9):973-976. Doi: 10.1097/00007611-199509000-00018.

140. Nakamura H, Noh JY, Itoh K, et al. Comparison of methimazole and propylthiouracil in patients with hyperthyroidism caused by Graves' disease. J Clin Endocrinol Metab. 2007;92(6):2157-2162. Doi: 10.1210/jc.2006-2135

141. Korelitz JJ, McNally DL, Masters MN, et al. Prevalence of thyrotoxicosis, antithyroid medication use, and complications among pregnant women in the United States. Thyroid. 2013;23(6):758-765. Doi: 10.1089/thy.2012.0488.

142. Andersen SL, Olsen J, Wu CS, Laurberg P. Birth defects after early pregnancy use of antithyroid drugs: a Danish nationwide study. J Clin Endocrinol Metab. 2013;98(11):4373-4381. Doi: 10.1210/jc.2013-2831.

143. Rubin PC. Current concepts: beta-blockers in pregnancy. N Engl J Med. 1981;305(22):1323-1326. Doi: 10.1056/NEJM198111263052205.

144. Momotani N, Hisaoka T, Noh J, et al. Effects of iodine on thyroid status of fetus versus mother in treatment of Graves' disease complicated by pregnancy. J Clin Endocrino/ Metab. 1992;75(3):738-744. Doi: 10.1210/jcem.75.3.1517362.

145. Nedrebo BG, Holm PI, Uhlving S, et al. Predictors of outcome and comparison of different drug regimens for the prevention of relapse in patients with Graves' disease. Eur J Endocrinol. 2002;147(5):583-589. Doi: 10.1530/eje.0.1470583.

146. Laurberg P, Andersen SL. Therapy of endocrine disease: antithyroid drug use in early pregnancy and birth defects: time windows of relative safety and high risk? Eur J Endocrinol. 2014;171(1):R13-R20. Doi: 10.1530/EJE-14-0135.

147. Laurberg P. Remission of Graves' disease during anti-thyroid drug therapy: time to reconsider the mechanism? Eur J Endocrinol. 2006;155(6):783-786. Doi: 10.1530/eje.1.02295.

148. Bliddal S, Rasmussen AK, Sundberg K, et al. Antithyroid drug-induced fetal goitrous hypothyroidism. Nat Rev Endocrinol. 2011;7(7):396-406. Doi: 10.1038/nrendo.2011.34

149. McKenzie JM, Zakarija M. Fetal and neonatal hyperthyroidism and hypothyroidism due to maternal TSH receptor antibodies. Thyroid. 1992;2(2):155-159. Doi: 10.1089/thy.1992.2.155.

150. Abeillon-du Payrat J, Chikh K, Bossard N, et al. Predictive value of maternal second-generation thyroid-binding inhibitory immunoglobulin assay for neonatal autoimmune hyperthyroidism. Eur J Endocrinol. 2014;171(4):451-460. Doi: 10.1530/EJE-14-0254.

151. Cove DH, Johnston P. Fetal hyperthyroidism: experience of treatment in four siblings. Lancet. 1985; 1 (8426):430-432. Doi: 10.1016/s0140-6736(85)91148-1.

152. Amino N, Tanizawa O, Mori H, et al. Aggravation of thyrotoxicosis in early pregnancy and after delivery in Graves' disease. J Clin Endocrinol Metab. 1982;55(1):108-112. Doi: 10.1210/jcem-55-1-108.

153. Alexander EK, Pearce EN, Brent GA, et al. 2017 guidelines of the American Thyroid Association for the Diagnosis and Management of Thyroid Disease During Pregnancy and the Postpartum. Thyroid. 2017;27(3):315-389. Doi: 10.1089/thy.2016.0457.

154. Mandel SJ, Cooper DS. The use of antithyroid drugs in pregnancy and lactation. J Clin Endocrino/ Metab. 2001;86(6):2354-2359. Doi: 10.1210/jcem.86.6.7573. 
155. Pearce SH. Spontaneous reporting of adverse reactions to carbimazole and propylthiouracil in the UK. Clin Endocrinol (Oxf). 2004;61(5):589-594. Doi: 10.1111/j.1365-2265.2004.02135.x.

156. Perros P, Crombie AL, Matthews JN, Kendall-Taylor P. Age and gender influence the severity of thyroid-associated ophthalmopathy: a study of 101 patients attending a combined thyroid-eye clinic. Clin Endocrinol (Oxf). 1993;38(4):367-372. Doi: 10.1111/j.1365-2265.1993.tb00516.x.

157. Leger J, Gelwane G, Kaguelidou F, et al. French Childhood Graves' Disease Study Group: Positive impact of long-term antithyroid drug treatment on the outcome of children with Graves' disease: national long-term cohort study. J Clin Endocrinol Metab. 2012;97(1):110-119. Doi: 10.1210/jc.2011-1944.

158. Ohye H, Minagawa A, Noh JY, et al. Antithyroid drug treatment for graves' disease in children: a long-term retrospective study at a single institution. Thyroid. 2014;24(2):200-207. Doi: 10.1089/thy.2012.0612.

159. Rivkees SA, Szarfman A. Dissimilar hepatotoxicity profiles of propylthiouracil and methimazole in children. J Clin Endocrinol Metab. 2010;95(7):3260-3267. Doi: 10.1210/jc.2009-2546.

160. Ma C, Kuang A, Xie J, Liu G. Radioiodine treatment for pediatric Graves' disease. Cochrane Database Syst Rev. 2008;(3):CD006294. Doi: 10.1002/14651858.CD006294.pub2.
161. Coles AJ, Wing M, Smith S, et al. Pulsed monoclonal antibody treatment and autoimmune thyroid disease in multiple sclerosis. Lancet. 1999;354(9191):1691-1695. Doi: 10.1016/S0140-6736(99)02429-0.

162. Chen F, Day SL, Metcalfe RA, et al. Characteristics of autoimmune thyroid disease occurring as a late complication of immune reconstitution in patients with advanced human immunodeficiency virus (HIV) disease. Medicine (Baltimore). 2005;84(2):98-106. Doi: 10.1097/01.md.0000159082.45703.90.

163. Weetman AP. Graves' disease following immune reconstitution or immunomodulatory treatment: should we manage it any differently? Clin Endocrinol (Oxf). 2014;80(5):629-632. Doi: 10.1111/cen.12427.

164. Furmaniak J, Sanders J, Nunez Miguel R, Rees Smith B. Mechanisms of action of TSHR autoantibodies. Horm Metab Res. 2015;47(10):735-752. Doi: 10.1055/s-0035-1559648.

165. Gershengorn MC, Neumann S. Update in TSH receptor agonists and antagonists. J Clin Endocrinol Metab. 2012;97(12):4287-4292. Doi: 10.1210/jc.2012-3080

166. El Fassi D, Nielsen $\mathrm{CH}$, Hasselbalch $\mathrm{HC}$, Hegedus $\mathrm{L}$. The rationale for B lymphocyte depletion in Graves' disease: monoclonal anti-CD20 antibody therapy as a novel treatment option. Eur J Endocrinol. 2006;154(5):623-632. Doi: 10.1530/eje.1.02140.

\section{ИНФОРМАЦИЯ ОБ АВТОРАХ [AUTHORS INFO]}

Фадеев Валентин Викторович, д.м.н., профессор, член-корр. PAH [Valentin V. Fadeyev, MD, PhD, Professor]; адрес: ул. Погодинская, д. 1, стр. 1, 119992 Москва, Россия [address: 1-1 Pogodinskaya street. 119992 Moscow, Russia]; e-mail: walfad@mail.ru; ORCID: https://orcid.org/0000-0002-3026-6315; eLibrary SPIN: 6825-8417.

\section{ИНФОРМАЦИЯ:}

Рукопись получена: 08.06.2020. Одобрена к публикации: 11.06.2020. Опубликована online: 24.07.2020

\section{ЦИТИРОВАТЬ}

Фадеев В.В. По материалам клинических рекомендаций Европейской тиреоидной ассоциации по диагностике и лечению тиреотоксикоза при болезни Грейвса 2018 года // Клиническая и экспериментальная тиреоидология. - 2020. — T. 16. — №1. — C. 4-20. doi: https://doi.org/10.14341/ket12474

\section{CITE THIS ARTICLE:}

Fadeyev VV. Review of European Thyroid Association Guideline (2018) for the Management of Graves' Hyperthyroidism. Clinical and experimental thyroidology. 2020;16(1): 4-20. doi: https://doi.org/10.14341/ket12474 